\title{
Coincidence cloning recovery of Brucella melitensis RNA from goat tissues: advancing the in vivo analysis of pathogen gene expression in brucellosis
}

Paola M. Boggiatto, Daniel Fitzsimmons, Darrell O. Bayles, David Alt, Catherine E. Vrentas ${ }^{*}$ and Steven C. Olsen

\begin{abstract}
Background: Brucella melitensis bacteria cause persistent, intracellular infections in small ruminants as well as in humans, leading to significant morbidity and economic loss worldwide. The majority of experiments on the transcriptional responses of Brucella to conditions inside the host have been performed following invasion of cultured mammalian cells, and do not address gene expression patterns during long-term infection.

Results: Here, we examine the application of the previously developed coincidence cloning methodology to recover and characterize B. melitensis RNA from the supramammary lymph node of experimentally-infected goats. Using coincidence cloning, we successfully recovered Brucella RNA from supramammary lymph nodes of B. melitensis-infected goats at both short-term (4 weeks) and long-term (38 weeks) infection time points. Amplified nucleic acid levels were sufficient for analysis of Brucella gene expression patterns by RNA-sequencing, providing evidence of metabolic activity in both the short-term and the long-term samples. We developed a workflow for the use of sequence polymorphism analysis to confirm recovery of the inoculated strain in the recovered reads, and utilized clustering analysis to demonstrate a distinct transcriptional profile present in samples recovered in long-term infection. In this first look at $B$. melitensis gene expression patterns in vivo, the subset of Brucella genes that was highly upregulated in long-term as compared to short-term infection included genes linked to roles in murine infection, such as genes involved in proline utilization and signal transduction. Finally, we demonstrated the challenges of qPCR validation of samples with very low ratios of pathogen:host RNA, as is the case during in vivo brucellosis, and alternatively characterized intermediate products of the coincidence cloning reaction.
\end{abstract}

Conclusions: Overall, this study provides the first example of recovery plus characterization of B. melitensis RNA from in vivo lymph node infection, and demonstrates that the coincidence cloning technique is a useful tool for characterizing in vivo transcriptional changes in Brucella species. Genes upregulated in long-term infection in this data set, including many genes not previously demonstrated to be virulence factors in mice or macrophage experiments, are candidates of future interest for potential roles in Brucella persistence in natural host systems.

Keywords: Brucella, Brucellosis, B. melitensis, Coincidence cloning, Pathogen RNA, RNA-Seq

*Correspondence: catherine.vrentas@ars.usda.gov

Infectious Bacterial Diseases Research Unit, National Animal Disease

Center, Agricultural Research Service, U.S. Department of Agriculture,

Ames, IA 50010, USA

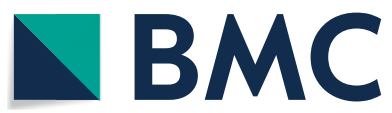

(c) The Author(s) 2018. This article is distributed under the terms of the Creative Commons Attribution 4.0 International License (http://creativecommons.org/licenses/by/4.0/), which permits unrestricted use, distribution, and reproduction in any medium, provided you give appropriate credit to the original author(s) and the source, provide a link to the Creative Commons license, and indicate if changes were made. The Creative Commons Public Domain Dedication waiver (http://creativecommons.org/ publicdomain/zero/1.0/) applies to the data made available in this article, unless otherwise stated. 


\section{Background}

Brucella are Gram-negative, facultative intracellular bacteria that cause brucellosis in animals and humans. Brucellosis is one of the most common bacterial zoonotic diseases worldwide with approximately 500,000 new infections annually [1]. Brucella melitensis infects primarily sheep and goats, resulting in abortion, decreased production, and infertility in infected animals. $B$. melitensis is also highly pathogenic to humans. Human brucellosis caused by $B$. melitensis has a high incidence in developing countries and is considered one of the seven neglected zoonoses by the World Health Organization (WHO) [2].

Brucella species have a complex pathophysiology, characterized by their ability to evade the host immune response. Brucella survive and replicate inside phagocytic cells of the immune system, primarily macrophages and dendritic cells, and modulate host cell function (reviewed in [3]). Phagocytic cells serve as an infection niche and also allow Brucella spp. to disseminate to other tissues, including the reticuloendothelial system and the reproductive tract of both males and females. Brucella spp. have evolved a variety of mechanisms for intracellular survival including inhibition of apoptosis of infected cells, remodeling of the phagocytic pathway, and modulation of host cell signaling inflammatory pathways [3-13]. These strategies enable long-term survival within infected cells and facilitate the establishment of chronic infection. Ultimately, the intracellular nature of Brucella spp. lends itself to the protracted and often clinically silent evolution of the disease.

The intracellular nature of Brucella not only limits its exposure to the host immune system, but also complicates the study of host-pathogen interactions in vivo, which requires an understanding of both the host's response to infection and the pathogen's response to the host. The intracellular environment poses a challenge for survival, as Brucella spp. face nutrient starvation, low $\mathrm{pH}$, and low oxygen tension conditions [14-17]. While Brucella lack classical virulence factors (e.g., exotoxins, cytolysins, exoproteases) $[18,19]$, many other virulence genes have been characterized, encompassing multiple functional categories, with an overrepresentation of genes involved in intracellular trafficking and vesicular transport, transcription, cell wall and membrane biogenesis, nucleotide transport and metabolism, and cell motility (reviewed in [20-22]). While a few studies have been performed utilizing tagged mutant libraries of Brucella in order to identify genes necessary for survival in the mammalian host [23-26], many genes associated with virulence were identified from studies done in cell culture using macrophage infections, or in vitro using pure Brucella cultures under different growth conditions. These studies have provided insight into the genes important for Brucella pathogenicity in model systems, yet very little is known regarding the gene expression profiles of Brucella within an infected host. Recently, Rossetti et al. [27] characterized the transcriptional profile of B. melitensis in experimentally-infected jejuno-ileal segments of calves over a 4-h time period. However, no studies have yet characterized Brucella transcriptional profiles during long-term natural host infection.

The current affordability of whole-genome transcriptome studies provides the ability to characterize gene expression profiles across large numbers of samples. However, our ability to apply these techniques during in vivo infections is limited by the availability of pathogen RNA in host-derived tissue samples, especially in the case of chronic infections with low bacterial loads and low ratios of pathogen RNA relative to host RNA. In order to circumvent this problem of excess host RNA, several techniques have been developed, including differential lysis of eukaryotic vs. prokaryotic cells, subtractive hybridization to enrich bacterial transcripts, and hybridization-based selection of bacterial transcripts (summarized by [28]). For Brucella, Rossetti et al. [29] developed a methodology for bacterial enrichment that involves both selective reduction of host transcripts and selective amplification of $B$. melitensis open reading frames with a set of 89 primers. These primers were validated at pathogen:host RNA ratios of 1:12.5, which is a much larger ratio than that expected for our lymph node samples in chronic infection.

Recently, Azhikina et al. [28] developed a coincidence cloning-based methodology for whole pathogen transcriptome analysis, which allows for isolation of representative bacterial RNA from small quantities of infected tissues in the absence of additional bacterial genomic sequence information. Coincidence cloning involves hybridization of excess bacterial genomic DNA with cDNA derived from RNA extracted from infected tissues, with subsequent selective amplification of the prokaryotic fraction of the cDNA sample. Therefore, coincidence cloning is potentially applicable to samples with very low concentrations of bacteria per weight of host tissue (estimated at $0.04 \%$, or a pathogen:host ratio of $1: 2500$, in the case of tuberculosis samples [30]). This methodology was previously utilized to characterize the transcriptome of Mycobacterium tuberculosis isolated from mouse lung tissues [28], and was able to identify upregulated genes in lung-derived samples from two different mouse strains [31].

Here, we examined whether coincidence cloning could be used to detect and characterize the transcriptome of B. melitensis strain $16 \mathrm{M}$ in the tissues of experimentally-infected goats. Application of the methodology to 
supramammary lymph node samples allowed for highcoverage RNA-sequencing analysis of samples from goats with short-term and long-term Brucella infections. We observed clustering of gene expression profiles for the long-term infection group, providing evidence that the method can be used for differential expression profiling. We also characterized some of the challenges related to the validation of results for low bacterial abundance systems. In sum, the data presented here indicate the utility of coincidence cloning in the study of host-pathogen interactions during Brucella spp. infection and provide the first characterization of the Brucella transcriptome post-dissemination in the natural host.

\section{Methods}

\section{Bacterial cultures}

Brucella melitensis strain $16 \mathrm{M}$ was obtained from the National Animal Disease Center (Ames, IA) culture collection. Frozen stock cultures used for experimental infection or reagent preparation were propagated on tryptose agar (Difco Laboratories, Detroit, MI) containing $5 \%$ bovine sera (TSA) for $72 \mathrm{~h}$ at $37{ }^{\circ} \mathrm{C}$ and $5 \% \mathrm{CO}_{2}$. Bacteria were harvested via resuspension in phosphatebuffered saline (PBS), and bacterial concentrations were determined via measurement of the optical density at $600 \mathrm{~nm}$ with a spectrophotometer plus an $\mathrm{OD}_{600} / \mathrm{CFU}$ calibration curve. Final concentrations of live bacteria used for animal challenges were determined by serial dilution and standard plate counts on TSA. For use in serology assays, strain $16 \mathrm{M}$ bacteria were grown on TSA for $48 \mathrm{~h}$ at $37^{\circ} \mathrm{C}$ and resuspended in PBS; bacterial concentrations were determined by standard plate counts. After incubation at $60{ }^{\circ} \mathrm{C}$ for $2 \mathrm{~h}$, and confirmation of inactivation by microbiological culture, aliquots of the culture suspension were stored at $-80{ }^{\circ} \mathrm{C}$ until use. Culture manipulations were performed in a certified biosafety cabinet in a select agent-registered space, using biosafety level (BSL)-3-level precautions.

\section{Experimental challenge of goats}

Seven female goats of approximately $1-3$ years of age were obtained from brucellosis-free herds. The group contained Toggenburg, Alpine, and Saanen breeds. After onsite acclimation for 2 weeks, animals were moved into an agricultural biosafety level (AgBSL)-3 facility at the National Animal Disease Center (NADC) in Ames, Iowa, and allowed to acclimate for an additional 2 weeks prior to intraconjunctival challenge with $10^{7} \mathrm{~B}$. melitensis strain $16 \mathrm{M}$. Animals were divided into short-term (4 weeks; $\mathrm{n}=3$; all pregnant) and long-term (38 weeks; $\mathrm{n}=4$; one pregnant, three non-pregnant) infection groups. All were maintained under AgBSL-3 housing until euthanasia.
Experimental challenge was confirmed by two methods: recovery of the challenge strain, and seroconversion. Conjunctival swabs were taken at 5 days post-challenge, plated onto Kuzdas and Morse (KM) media [32], and incubated at $37{ }^{\circ} \mathrm{C}$ in $5 \% \mathrm{CO}_{2}$ for 7 days to verify the presence of $B$. melitensis in each goat via colony morphology [33]. Isolates were confirmed as Brucella via polymerase chain reaction (PCR) using Brucella-specific primers for omp $2 a$ [34]. For serology, blood was obtained from the jugular vein at 0 and 4 weeks post-challenge in the shortterm group and at $0,2,4,8,12,23$, and 37 weeks postchallenge in the long-term group. Antibody responses pre- and post-experimental challenge were evaluated using a standard tube agglutination test [33].

Large animal isolation facilities were operated under guidelines approved by the United States Department of Agriculture/Agricultural Research Service (USDA/ ARS). All animal studies were performed under approval from the Institutional Animal Care and Use Committee (IACUC) at the NADC.

\section{Necropsy and tissue processing}

Goats were euthanized by intravenous injection of sodium pentobarbital (Sleepaway, Ft. Dodge Labs, Ft. Dodge, IA, USA) at two different time points post-challenge. Samples obtained at necropsy for evaluation of bacterial content included: lymphatic tissues (parotid, prescapular (superficial cervical), retropharyngeal, and supramammary), placentome or uterus, and conjunctival swabs.

Tissue samples for bacterial enumeration were processed as previously reported $[35,36]$. Briefly, approximately $1 \mathrm{~g}$ of each tissue sample was individually ground in $2 \mathrm{ml}$ of PBS $(\mathrm{pH}=7.2)$ using sterile glass Dounce homogenizers. Tenfold serial dilutions $\left(10^{-1}\right.$ to $\left.10^{-8}\right)$ of each suspension of each tissue were generated, and $100 \mu \mathrm{l}$ of each dilution were plated onto $\mathrm{KM}$ and incubated at $37{ }^{\circ} \mathrm{C}$ in $5 \% \mathrm{CO}_{2}$ for 7 days. The conjunctival swabs were streaked directly onto the surface of KM plates. All plates were incubated at $37^{\circ} \mathrm{C}$ and $5 \% \mathrm{CO}_{2}$ for $72 \mathrm{~h}$, and isolates were identified as Brucella on the basis of colony morphology, growth characteristics, and a pan-Brucella PCR assay for the omp $2 a$ gene with the following primer set: $5^{\prime}$ TGG TCT GAA GTA TCA GGC TAC GCA $3^{\prime} / 5^{\prime}$ CCC AAG CAT TGT CTT CAG CAA CAG 3 '.

\section{Isolation of $B$. melitensis $16 \mathrm{M}$ genomic DNA}

Total bacterial genomic DNA was prepared from an overnight culture of B. melitensis $16 \mathrm{M}$ stock using the Ultra-Deep Microbiome Prep kit (Molzym Life Science, Germany) according to manufacturer's recommendations. 


\section{RNA isolation and CDNA preparation}

Approximately $50-100 \mathrm{mg}$ of each flash-frozen supramammary lymph node (SMLN) sample were pulverized with a pestle in a chilled mortar in liquid nitrogen and then immediately added to $1 \mathrm{ml}$ of TRIzol reagent (ThermoFisher) and processed according to manufacturer's instructions. The aqueous phase was collected and further purified using the Purelink RNA Mini kit (ThermoFisher), according to manufacturer's recommendations. Residual DNA was removed from RNA samples by treating $1 \mu \mathrm{g}$ of total RNA from each of the samples with $1 \mu \mathrm{l}(2 \mathrm{U})$ of DNase I and 1 $\mu \mathrm{l}$ of $10 \times$ DNase I buffer (Life Technologies, Carlsbad, CA) in a total reaction volume of $11 \mu \mathrm{l}$. Samples were incubated at $37{ }^{\circ} \mathrm{C}$ for $30 \mathrm{~min}$. for digestion and subsequently at $65^{\circ} \mathrm{C}$ for $10 \mathrm{~min}$. to inactivate the enzyme followed by the addition of $1.11 \mu \mathrm{l}$ of $5 \mathrm{mM}$ EDTA.

RNA quality was assessed with an Agilent Bioanalyzer, using the RNA 6000 Pico kit (Agilent, Santa Clara, CA). All extracted samples from SMLN (combination of host and pathogen RNA) had Bioanalyzer RIN scores of $\geq 7.7$, with an average RIN score of 8.1 (Additional file 1: Table S1). RNA and DNA concentrations were measured using a NanoDrop (ThermoFisher).

cDNA was generated from total sample RNA using the method described in Azhikina et al. [28]. The first cDNA strand was synthesized using BR and SMART primers (Additional file 2: Table S2). Eleven $\mu$ l of each DNase I-digested sample was mixed with $1 \mu \mathrm{l}(10 \mathrm{pmol})$ BR and $1 \mu \mathrm{l}(10 \mathrm{pmol})$ SMART primers, incubated at $70{ }^{\circ} \mathrm{C}$ for $2 \mathrm{~min}$, and then held on ice for $10 \mathrm{~min}$. For synthesis of first-strand cDNA, all $13 \mu \mathrm{l}$ of annealed RNA were mixed with $0.5 \mu \mathrm{l}$ of PrimeScript reverse transcriptase (RT) and the corresponding buffer (Clontech, Mountain View, CA) and incubated at $37{ }^{\circ} \mathrm{C}$ for $10 \mathrm{~min}$, at $42{ }^{\circ} \mathrm{C}$ for $120 \mathrm{~min}$, and at $95^{\circ} \mathrm{C}$ for $5 \mathrm{~min}$. Second-strand synthesis of cDNA was performed using 5S primer (Additional file 2: Table S2) and PrimeStar GXL polymerase and the corresponding buffer (Clontech, Mountain View, CA) for 30 cycles of $98^{\circ} \mathrm{C}$ for $10 \mathrm{~s}, 64^{\circ} \mathrm{C}$ for $20 \mathrm{~s}$, and $68{ }^{\circ} \mathrm{C}$ for $5 \mathrm{~min}$. Samples were then held at $68{ }^{\circ} \mathrm{C}$ for $10 \mathrm{~min}$ and then stored at $4{ }^{\circ} \mathrm{C}$. The resulting cDNA was purified with a QIAquick PCR purification kit according to manufacturer's recommendations (Qiagen, Valencia, CA).

To generate culture-derived RNA for coincidence cloning, total RNA from mid-log liquid cultures of strain B. melitensis $16 \mathrm{M}$, cultured at $37^{\circ} \mathrm{C}$ in BBL Brucella Broth (BD Biosciences, San Jose, CA), was isolated from cell pellets preserved with RNAProtect (ThermoFisher) using the PureLink RNA Mini Kit and subsequent DNase digestion, according to manufacturer's recommendations.

\section{Coincidence cloning procedure}

Coincidence cloning was performed as described by Azhikina et al. [28]. Separately, $1 \mu \mathrm{g}$ of genomic DNA isolated from an overnight culture of B. melitensis $16 \mathrm{M}$ and $1 \mu \mathrm{g}$ of cDNA from each lymph node sample were enzymatically digested with RsaI (New England Biolabs, Ipswich, MA) for $4 \mathrm{~h}$ at $37^{\circ} \mathrm{C}$ in the corresponding buffer, followed by RsaI inactivation at $65^{\circ} \mathrm{C}$ for $10 \mathrm{~min}$. The fragments were ligated to specific suppression adapters: adapter I (T7NotSrf and Srf_10 mixture) with the genomic DNA, and adapter II (T7NotRsa and Rsa_10 mixture) with sample cDNA. Adapter-linked genomic DNA and adapter-linked sample cDNA were then mixed in hybridization buffer (50 mM HEPES, $\mathrm{pH} 8.3 ; 0.5 \mathrm{M}$ $\mathrm{NaCl} ; 0.02 \mathrm{mM}$ EDTA, $\mathrm{pH} 8.0$ ) and incubated at $99{ }^{\circ} \mathrm{C}$ for $5 \mathrm{~min}$. (denaturation) followed by $68{ }^{\circ} \mathrm{C}$ for $18 \mathrm{~h}$ (renaturation).

The first PCR reaction (PCR1) was performed by combining $1 \mu \mathrm{l}$ of the hybridized DNA-cDNA mixture with the external primer T7 (10 pmol; Additional file 2: Table S2) and PrimeStar GXL polymerase with corresponding PrimeStar Max buffer (Clontech, Mountain View, CA). The PCR1 reaction was carried out for 20 cycles of $98^{\circ} \mathrm{C}$ for $10 \mathrm{~s}, 64{ }^{\circ} \mathrm{C}$ for $20 \mathrm{~s}$, and $68^{\circ} \mathrm{C}$ for $3.5 \mathrm{~min}$, followed by a final hold step of $68^{\circ} \mathrm{C}$ for $10 \mathrm{~min}$. The second PCR reaction (PCR2) was performed using $1 \mu \mathrm{l}$ of a 1:10 dilution of PCR1 product as a template, the internal primers Not1Srf $(10 \mathrm{pmol})$ and Not1Rsa $(10 \mathrm{pmol})$, and PrimeStar GXL polymerase with corresponding PrimeStar Max buffer (Clontech, Mountain View, CA) (Additional file 2: Table S2). The PCR2 reaction was performed using the same cycling conditions indicated for the PCR1 reaction. The product of the PCR2 reaction, or the "coincidence cloning product", was purified using a QIAquick PCR Purification kit according to manufacturer's recommendations (Qiagen, Valencia, CA).

\section{Library preparation and RNA-sequencing (RNA-Seq)}

Amplicons were used for preparation of indexed libraries employing the Nextera XT DNA sample preparation and index kits according to manufacturer's directions (Illumina, San Diego, CA). Resulting libraries were normalized, pooled and sequenced using the MiSeq v2 300 Cycle reagent kit, yielding $2 \times 150$-bp paired-end reads on the Illumina MiSeq platform (Illumina, San Diego, CA).

\section{Bioinformatic analysis}

Paired-end sequencing reads for each sample were trimmed with Trimmomatic v. 0.35 [37]. Trimmed reads were aligned to a $B$. melitensis $16 \mathrm{M}$ reference genome (NCBI accessions NC_003317 and NC_003318, for chromosome I and II, respectively) with the bowtie $2 \mathrm{v}$. 2.2.3 
aligner [38]. HTSeq-count v. 0.6.1 was used to process the alignment files into gene-wise counts of reads mapped to the annotated genes in the reference genome [39]. SeqMonk v. 1.35 [40] was used to visualize the mapped reads and to perform basic quality control for the analysis. Cluster analyses were performed using R [41] and the following R packages: DESeq2 [42], gplots [43], ggplot2, PoiClaClu [44], RColorBrewer [45], magrittr [46], genefilter [47], and pheatmap [48]. The detection of insertions and deletions as compared to the B. melitensis $16 \mathrm{M}$ reference genome (NC_003317.1 and NC_003318.1) was performed using variant calling by FreeBayes [49] and SNVer ("SNVer for Individual Sequencing") [50]. A filter requiring $>50$ mapped reads at the indel location was applied. Indels presented in this manuscript were filtered for significance using a Bonferroni correction of $\mathrm{p}=0.05$ / number of independent tests, and only significant reads are displayed in Additional file 6.

\section{Endpoint PCR reactions}

To non-quantitatively detect the presence of $B$. melitensis $16 \mathrm{M}$ in cDNA samples, we utilized endpoint PCR reactions with Phusion DNA polymerase (New England Biolabs, Ipswich, MA), separated on $1 \%$ agarose gels with GelRed stain. The BMEI1305 primers (Additional file 2: Table S2) were used at a final concentration of $0.5 \mu \mathrm{M}$. Cycling conditions were as follows: $30 \mathrm{~s}$ at $98{ }^{\circ} \mathrm{C}$ denaturation step; 40 cycles of $10 \mathrm{~s}$ at $98{ }^{\circ} \mathrm{C}, 20 \mathrm{~s}$ at $64{ }^{\circ} \mathrm{C}$, and $15 \mathrm{~s}$ at $72{ }^{\circ} \mathrm{C}$; and $2 \mathrm{~min}$ of final elongation at $72{ }^{\circ} \mathrm{C}$. The template for endpoint PCR reactions ( $25 \mu \mathrm{l}$ total volume in $1 \times$ Phusion HF buffer) was double-stranded cDNA prepared from SMLN samples via the BR/SMART process as described above. The cDNA generated from RNA extracted from overnight B. melitensis $16 \mathrm{M}$ cultures, and processed in parallel to the lymph node samples, was used as a positive control. Negative controls, containing no added template, were run in parallel in all PCR experiments.

\section{qPCR and qRT-PCR assays}

qPCR was utilized to determine the relative levels of transcription of a set of $5 \mathrm{~B}$. melitensis $16 \mathrm{M}$ genes in long-term infection coincidence cloning samples. Primers were designed for each gene using NCBI's PrimerSelect tool, and sequences are provided in Additional file 2: Table S2. The PCR1 product from the samples was used as a template in reactions performed with the SuperScript III Platinum SYBR Green One-Step qRT-PCR kit (ThermoFisher), following the manufacturer's instructions (omitting the cDNA synthesis step). Briefly, reactions included $0.2 \mu \mathrm{M}$ of each primer and $1 \mu \mathrm{l}$ of a $1: 10$ dilution of PCR1 product, and were cycled on a RotorGene Q (Qiagen, Valencia, CA) using the following program: 2 min at $95{ }^{\circ} \mathrm{C} ; 40$ cycles of $3 \mathrm{~s}$ at $95{ }^{\circ} \mathrm{C}$ and $30 \mathrm{~s}$ at $60{ }^{\circ} \mathrm{C}$. For the comparison of entA and $n d v B$, a three-step cycling protocol was used for both primers to improve efficiency for the $n d v B$ primer: $15 \mathrm{~s}$ at $95{ }^{\circ} \mathrm{C}, 30 \mathrm{~s}$ at $55^{\circ} \mathrm{C}$, and $30 \mathrm{~s}$ at $72{ }^{\circ} \mathrm{C}$ (also for 40 cycles). Amplification was detected using the SYBR Green signal. Separate endpoint PCR reactions were performed and the products were subsequently separated on an agarose gel to confirm the presence of single products for each primer set. Melt curve analysis was performed on each qPCR reaction to confirm the presence of a single peak per reaction. A template dilution series across a series of five concentrations (tenfold dilutions of template) was performed for each primer set to assess PCR efficiency. Average \% efficiency values for the two-step cycling were as follows: eryK (erythritol kinase), 98\%; $d k s A, 94 \%$; ent $A$ (enterobactin), 99\%; ribE (riboflavin synthase alpha subunit), $94 \%$. For the comparison of ent $A$ and $n d v B$ under three-step cycling conditions, the efficiency of $n d v B$ was $82 \%$ vs. $92 \%$ efficiency for entA. We incorporated a correction factor to each $C_{t}$ value based on the efficiency as compared to the efficiency of the entA primers.

$C_{t}$ values were calculated using the Rotor-Gene $Q$ software with manual determination of the threshold. $C_{t}$ data for each gene were averaged across biological replicates. For some of the primer sets, amplification was observed in the no template control (presumably reflecting primerdimer formation) before 40 cycles; however, $C_{t}$ values for no template control reactions were $>10$ cycles beyond $C_{t}$ values for the experimental reactions in each case.

qRT-PCR was also attempted on short-term lymph node RNA samples using the gene-specific procedures described above. Prior to the cycling step, a $5 \mathrm{~min}$ hold step at $50{ }^{\circ} \mathrm{C}$ was utilized to convert RNA to cDNA via the amplification primers as gene-specific primers.

\section{Results \\ Description of $B$. melitensis $16 \mathrm{M}$ infection in experimentally inoculated goats}

Goats were experimentally challenged with $B$. melitensis $16 \mathrm{M}$ for all experiments described below. Animals were placed into one of two groups: short-term infection (defined as 4 weeks post-challenge) or long-term infection (defined as 38 weeks post-challenge). The challenge strain was recovered from conjunctival swabs taken 5 days post-challenge, confirming successful infection. Both groups of animals demonstrated an increase in anti-Brucella serum antibodies against B. melitensis $16 \mathrm{M}$ (Fig. 1), additionally confirming infection. In the longterm infection group, antibody titers peaked at 8 weeks post-challenge and remained fairly stable with a minor decrease by the time animals were necropsied (Fig. 1). 


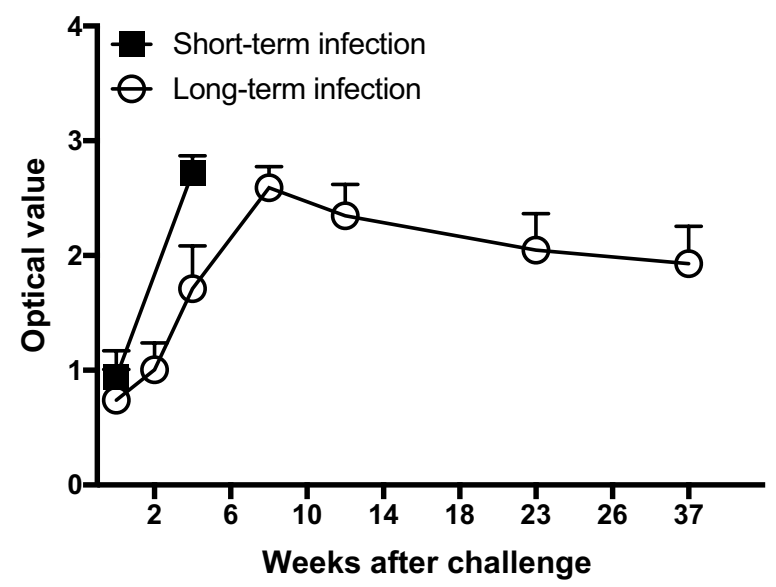

Fig. 1 Anti-Brucella antibody production in response to B. melitensis $16 \mathrm{M}$ following infection. The standard tube agglutination test was used to measure anti-Brucella antibodies in serum collected at different time points post-infection for both the short-term (closed squares) and long-term (open circles) infection groups. Data points reflect the average of the optical values across each set of goats, \pm the standard error of the mean

\section{Bacterial tissue colonization in short- and long-term infection}

Lymphoid (parotid, prescapular, and supramammary lymph nodes) and placentome/uterus samples were harvested during necropsy at 4 weeks (short-term infection) or at 38 weeks (long-term infection) post-challenge and were used to determine the number of $B$. melitensis $16 \mathrm{M}$ cells in the infected tissue. In the short-term infection group, Brucella were recovered from all tissues analyzed (Table 1), with the placentome containing the highest average $\log _{10} \mathrm{CFU} / \mathrm{g}$ (geometric mean; $6.95 \pm 0.81$ ). In contrast, we were unable to recover any viable Brucella from any of the tissues tested from the long-term infection group (Table 1).

\section{Attempt to detect low levels of B. melitensis $16 \mathrm{M}$ in lymph nodes via existing nucleic acid methods}

Recently, Wang et al. [51] demonstrated that low levels of Brucella melitensis could be identified more effectively via detection of RNA of highly expressed genes by RT-PCR, as compared to detection of genomic DNA by PCR, due to the presence of higher copy numbers of the RNAs. Wang et al. selected a B. melitensis gene for detection (BMEI1305, encoding the porin Omp2b) based on its absolute level of gene expression in a culture of $B$. melitensis grown to an $\mathrm{OD}_{600}$ of 1.0 at $37^{\circ} \mathrm{C}$ in tryptic soy broth. The authors concluded that the BMEI1305 primer set is a candidate for ultrasensitive detection of the presence of Brucella. Since primers developed for BMEI1305 detection were designed based on gene expression levels in bacterial culture, and not an in vivo system, we wanted to determine if we could use this method to detect very low levels of bacteria in B. melitensis 16M-infected lymph nodes.

cDNA samples from the supramammary lymph nodes (SMLN) of each animal, prepared using the BR/SMART method, were used as templates for 40-cycle endpoint PCR reactions. cDNA prepared from an overnight $B$. melitensis $16 \mathrm{M}$ culture was used as a positive control, resulting in a band of approximately 180 base pairs (bp) in size, which is the expected product from the BMEI1305 primers (Fig. 2a, lane 9). However, with $0.5 \mu$ l of shortterm or long-term lymph node cDNA added as template per reaction, the main product in each reaction was a primer-dimer band (Fig. 2a, lanes 1-8), as opposed to the main expected product. Dilution of the cDNA by up to $100 \times$ did not improve amplification (data not shown).

The absence of observable amplification could potentially be explained by the low levels of Brucella CFUs/g observed for the short-term lymph node tissues via culture methods (Table 1). Assuming an approximate value of $10^{3} \mathrm{CFUs} / \mathrm{g}$, based on plated bacterial counts, homogenization of $100 \mathrm{mg}$ of tissue for RNA processing would result in a theoretical maximum of only 100 CFUs per RNA sample, or $\approx 1 \mathrm{CFU} / \mu \mathrm{l}$ of RNA sample. This is at the limit of detection for the BMEI1305 primers that was reported for Wang et al. [51] and would require that extraction of pathogen RNA from the tissue samples be highly efficient. Alternatively, the highly abundant competing binding sites on the goat nucleic acid present in each sample may interfere with the PCR reactions. Assuming 500,000 mRNAs/eukaryotic cell, 5000 mRNAs/prokaryotic cell, and a mass of $1 \times 10^{-9} \mathrm{~g}$ per mammalian cell, $1 \mathrm{~g}$ of lymph node tissue would contain $\approx 10^{9}$ host cells, as compared to $10^{3}$ bacterial cells, meaning that we could estimate the presence of $5 \times 10^{14}$ host mRNAs in the gram of tissue vs. $5 \times 10^{6}$ bacterial mRNAs. This estimated bacterial RNA: host RNA ratio $\left(1: 10^{8}\right)$ is well below the expected bacterial RNA percentage $\left(0.1-0.2 \%\right.$, or a $1: 10^{3}$ ratio) that was estimated in the application of coincidence cloning by Azhikina et al. [28].

Therefore, in order to further assess the potential for nucleic acid detection using the BMEI1305 primers with lymph node samples, we characterized PCR reactions with increasing dilutions of $B$. melitensis cDNA derived from overnight bacterial cultures. The presence of host (goat) cDNA did not preclude amplification of $B$. melitensis cDNA when present at a ratio of $1: 10^{4}$ pathogen cDNA:host cDNA (Fig. 2b, c). However, by a dilution of bacterial cDNA to $10^{4}-10^{5}$, amplification of the expected band exhibited significant competition with offtarget amplicons (Fig. 2b, lanes 2-7). We conclude that to characterize the nucleic acid inside $B$. melitensis $16 \mathrm{M}$ 


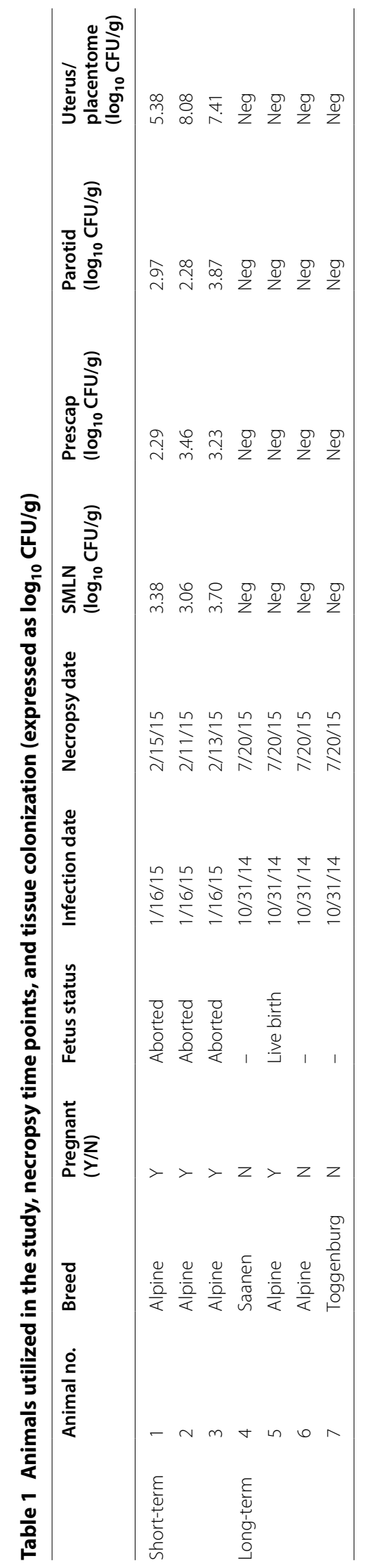


Fig. 2 PCR methodologies with goat lymph node samples. a Attempt at detection of Brucella transcripts by endpoint RT-PCR. The BMEl1305 primers were used to amplify CDNA templates $(0.5 \mu \mathrm{l}$ each) derived from long-term samples (lanes 1-4), short-term samples (lanes 5-8; one sample reflected a short-term goat that was not included in the coincidence cloning profiling), or a B. melitensis culture cDNA sample as a positive control (lane 9), for 40 cycles. The culture cDNA sample was prepared in parallel to the lymph node cDNA samples, using equivalent starting amounts of total DNA; the red arrow indicates the amplified band of interest. $N C=$ negative control with no template. Numbers presented to the left of each gel $(\mathbf{a}-\mathbf{c})$ are sizes of DNA ladder bands in base pairs. $\mathbf{b}$ Assessment of impacts of template dilution on amplification. As in (a), the BMEI1305 primers were used to amplify cDNA templates, in this case for 35 cycles. For lanes 2-7, $0.5 \mu \mathrm{l}$ aliquots of serially-diluted B. melitensis culture-derived cDNA were added to each reaction; dilutions are indicated above each lane. In lanes 8 and 9, $0.5 \mu$ l of diluted bacterial cDNA was mixed with $0.5 \mu \mathrm{l}$ of undiluted host CDNA in each reaction, with the bacterial dilution indicated above each lane. $N C=$ negative control with no template. $\mathbf{c}$ Additional assessment of impacts of host CDNA template on PCR amplification, with reactions as described in (b) for 35 cycles. Dilution factors above each lane indicate the dilution factor of the culture-derived cDNA added to the reaction. Since multiple background bands were observed in the BMEl1305 reactions, we also completed negative control PCR reactions with the NdvB (lane 7) and DksA (lane 9) primers to demonstrate the absence of contamination in reactions. "+ control" reactions for NdvB (lane 8 ) and DksA (lane 10) contained $0.5 \mu \mathrm{l}$ of culture-derived cDNA template

cells in lymph nodes, a more sensitive methodology with selective amplification of bacterial RNA is required.

\section{Detection and characterization of Brucella melitensis $16 \mathrm{M}$ via coincidence cloning}

We next examined whether coincidence cloning (Fig. 3) could be used for robust detection and characterization of the transcriptome of B. melitensis $16 \mathrm{M}$ in tissues from infected hosts. In selecting a tissue type for further processing, multiple sites of Brucella dissemination (as determined from the short-term culture data) were assessed for RNA quality. The quality of RNA from placental samples in short-term infected animals was not suitable for downstream RNA analysis, with RIN scores of $<6$. However, RNA from lymph node samples was intact (Additional file 3: Table S3). As SMLN samples reflect a site of systemic dissemination of Brucella (based on intra-conjunctival infection), we selected RNA samples derived from these lymph nodes for further analysis.

For both the short-term and long-term infection groups, Brucella RNA was recovered from the samples, as indicated by sequencing reads mapping to the Brucella melitensis $16 \mathrm{M}$ genome. This indicates that even when bacterial cells are not recovered from lymph node via Dounce homogenization, Brucella cells can be present in the lymph node tissue. For example, bacterial

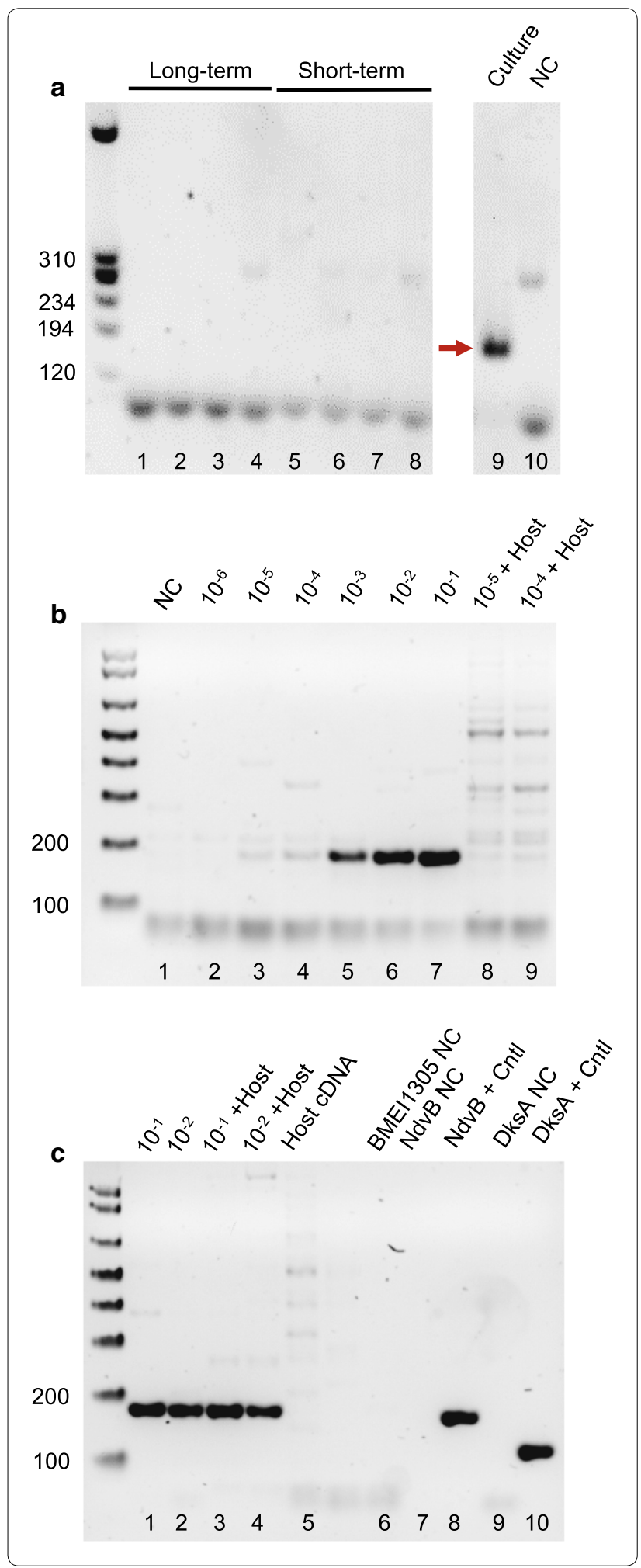

cells may be retained internally in tissue samples posthomogenization, or retained internally inside intact macrophages or macrophage compartments. For each of the 


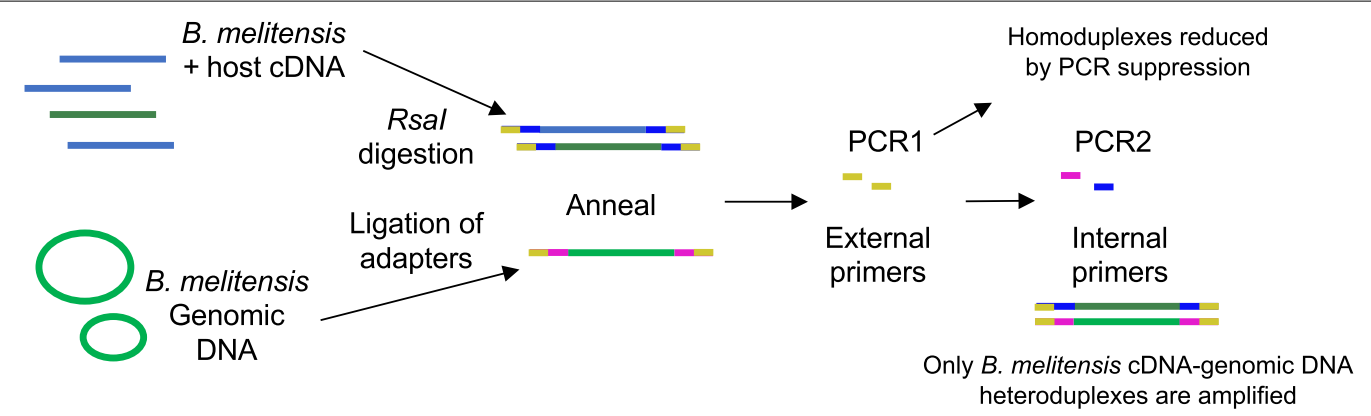

Fig. 3 Overview of coincidence cloning procedure. Methodology is based on Azhikina et al. [28]. RNA extracted from SMLN tissues from each goat was used to generate total cDNA containing both host (blue) and bacterial (dark green) CDNA. Total cDNA and B. melitensis 16M total genomic DNA are fragmented using a restriction enzyme and the ends ligated with different suppressive adaptors (bacterial, host cDNA: yellow-blue; bacterial genomic cDNA: yellow-pink). Each cDNA sample is mixed with digested genomic DNA, and the mixture denatured and renatured in the presence of excess gDNA, generating both gDNA/gDNA homodimers and gDNA/cDNA heterodimers of complementary strands. The samples then undergo a two-step PCR amplification, resulting in selective enrichment of bacterial cDNA fragments. Libraries were prepared from amplified products and sequenced to obtain profiles of $B$. melitensis $16 \mathrm{M}$ gene expression within the tissue of infected hosts

samples analyzed, approximately 1,000,000-1,500,000 read pairs were generated from sequencing, $\approx 75 \%$ of which mapped to annotated genes in the $16 \mathrm{M}$ genome in each case as determined by analysis by HTSeq (Table 2). This result indicates that the bacterial transcriptome was enriched evenly across samples, as compared to the genomic DNA used for coincidence cloning capture.

Next, we characterized the gene expression profile for each of the experimental groups. A full list of expression values for each $B$. melitensis $16 \mathrm{M}$ gene in short-term and in long-term infection is provided in Additional file 4. The top 100 genes ranked by expression from each of the experimental groups, based on counts normalized to gene and library size (FPKM), were categorized by functional annotation based on cluster of orthologous group categories (COG). The lists of annotated genes are included in Additional file 5, sorted by expression level for either the short-term or long-term samples. For the top 100 expressed genes in the short-term samples, we observed the following categories with the greatest representation: amino acid transport and metabolism (9.7\%); replication, recombination, and repair (8.6\%); and transcription (6.5\%) (Fig. 4a). For the top 100 expressed genes in the long-term samples, we observed the highest percentage of genes in the categories of amino acid transport and metabolism (8.2\%); lipid transport and metabolism (7.1\%); translation, ribosomal structure and biogenesis (7.1\%); and replication, recombination and repair (7.1\%) (Fig. 4b). Therefore, the gene profile for both groups reflects a bacterial population that is metabolically active.

\section{Examining methodologies for verification of sample reads} When working with very low levels of $B$. melitensis cells per sample, environmental contamination, and/or sample cross-contamination, are a significant concern. Therefore, we examined two lines of evidence to determine whether the recovered RNA was from in vivo bacteria in the original lymph node samples, or due to contamination. The two lines of evidence considered were: (a) indel (insertion/deletion) analysis as compared to the B. melitensis $16 \mathrm{M}$ reference genome, and (b) clustering

Table 2 Mapped reads per sample, generated from HTSeq-count mapping of reads to the $B$. melitensis $16 \mathrm{M}$ reference genome

\begin{tabular}{lcclll}
\hline Goat \# & Total read pairs & Pairs in genes & Pairs not in genes & Pairs not mapping & \% in genes \\
\hline 1 & $1,115,293$ & 838,577 & 272,050 & 4666 & 75 \\
2 & $1,400,935$ & $1,067,233$ & 328,057 & 5645 & 76 \\
3 & $1,010,360$ & 760,249 & 246,313 & 3798 & 75 \\
4 & $1,544,084$ & $1,199,374$ & 338,847 & 5863 & 78 \\
5 & $1,096,032$ & 830,054 & 262,052 & 3926 & 76 \\
6 & 968,576 & 720,841 & 244,936 & 2799 & 74 \\
7 & $1,266,995$ & 968,974 & 293,345 & 4676 & 76 \\
\hline
\end{tabular}




\section{a Short-term Gene Distribution}

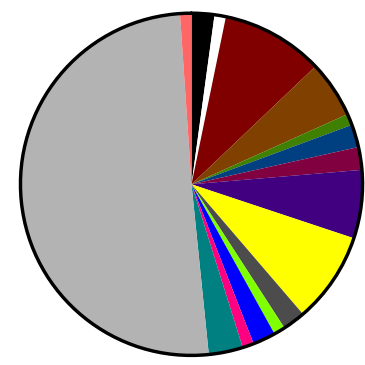

$2.15 \%$ Energy production and conversion (C)

$\square 1.08 \%$ Cell cycle control and mitosis (D)

9.68\% Amino acid transport and metabolism (E)

$\square 5.38 \%$ Carbohydrate transport and metabolism (G)

$\square 1.08 \%$ Coenzyme transport and metabolism $(\mathrm{H})$

$\square 2.15 \%$ Lipid transport and metabolism (I)

$\square 2.15 \%$ Translation, ribosomal structure and biogenesis (J)

$\square 6.45 \%$ Transcription (K)

$\square 8.60 \%$ Replication, recombination, and repair (L)

$\square 2.15 \%$ Cell wall/membrane/envelope biogenesis (M)

$\square 1.08 \%$ Postranslational modification, protein turnover, chaperones $(\mathrm{O})$

2.15\% Inorganic ion transport and metabolism $(\mathrm{P})$

$\square 1.08 \%$ Secondary structure $(Q)$

$\square 3.23 \%$ General function prediction only--poorly characterized (R)

$\square 50.54 \%$ Unknown function (S) + Hypothetical

$\square 1.08 \%$ Signal transduction mechanisms $(\mathrm{T})$

\section{b Long-term Gene Distribution}

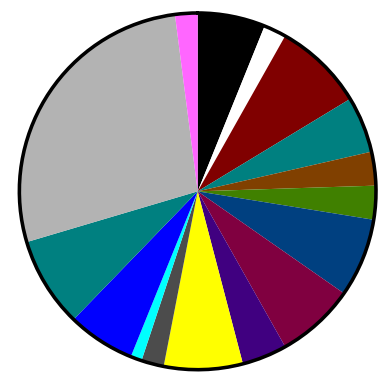

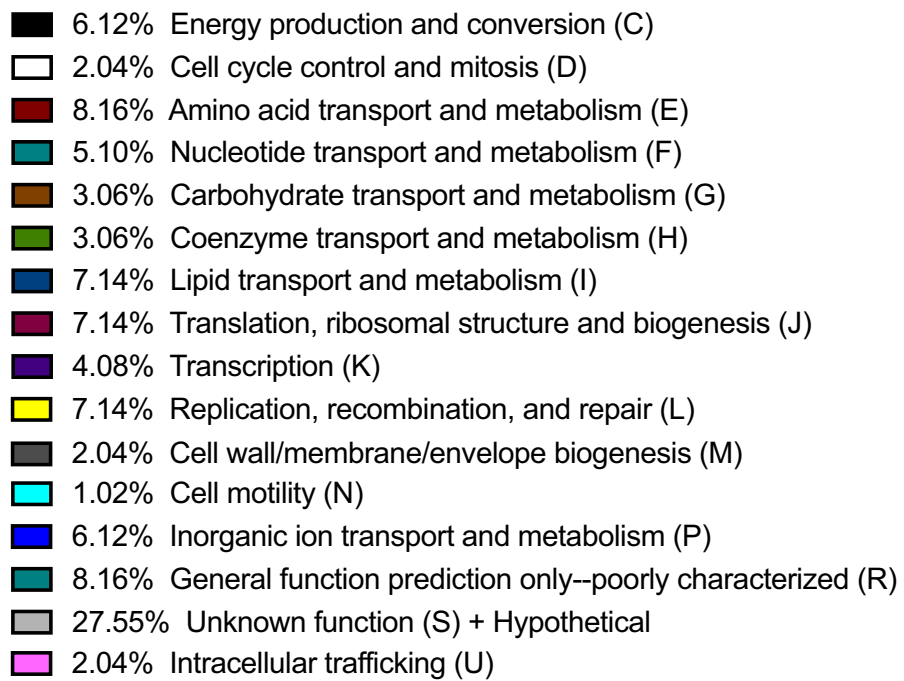

Fig. 4 B. melitensis genes transcribed in SMLN from goats with short-term (a) or long-term (b) infections. For each sample set, the 100 genes with the highest levels of expression, based on normalization of counts to gene size as quantified by SeqMonk (FPKM), were categorized by COG category to generate the percentages in the pie charts. COG categories were retrieved from the PHIDIAS portal (www.phidias.us/bbp)

analysis of the samples, as compared to a set of comparison samples processed in parallel.

First, indel analysis (Fig. 5) was performed to identify insertions and deletions as compared to the B. melitensis $16 \mathrm{M}$ reference genome, in the seven SMLN-derived samples as well as a set of samples derived from coincidence cloning of B. melitensis RNA from bacterial cultures of the same master stocks in our laboratory. In coincidence cloning, only cDNA sequences matching the corresponding gDNA capture sequences should be recovered at the end of the procedure. Any sequence variations in the culture strain (used for both gDNA production and experimental inoculation) from the published reference should be observed in the resulting sequencing reads. Indeed, patterns for the tissue-derived samples were consistent with patterns for the reference culture samples. A table of indels across samples, generated by SNVer, is provided in Additional file 6. The majority of indels associated with the culture comparison samples were found in either all of the samples, including the culture controls (highlighted in green), or in all but one of the samples (highlighted in yellow); no indels were identified 


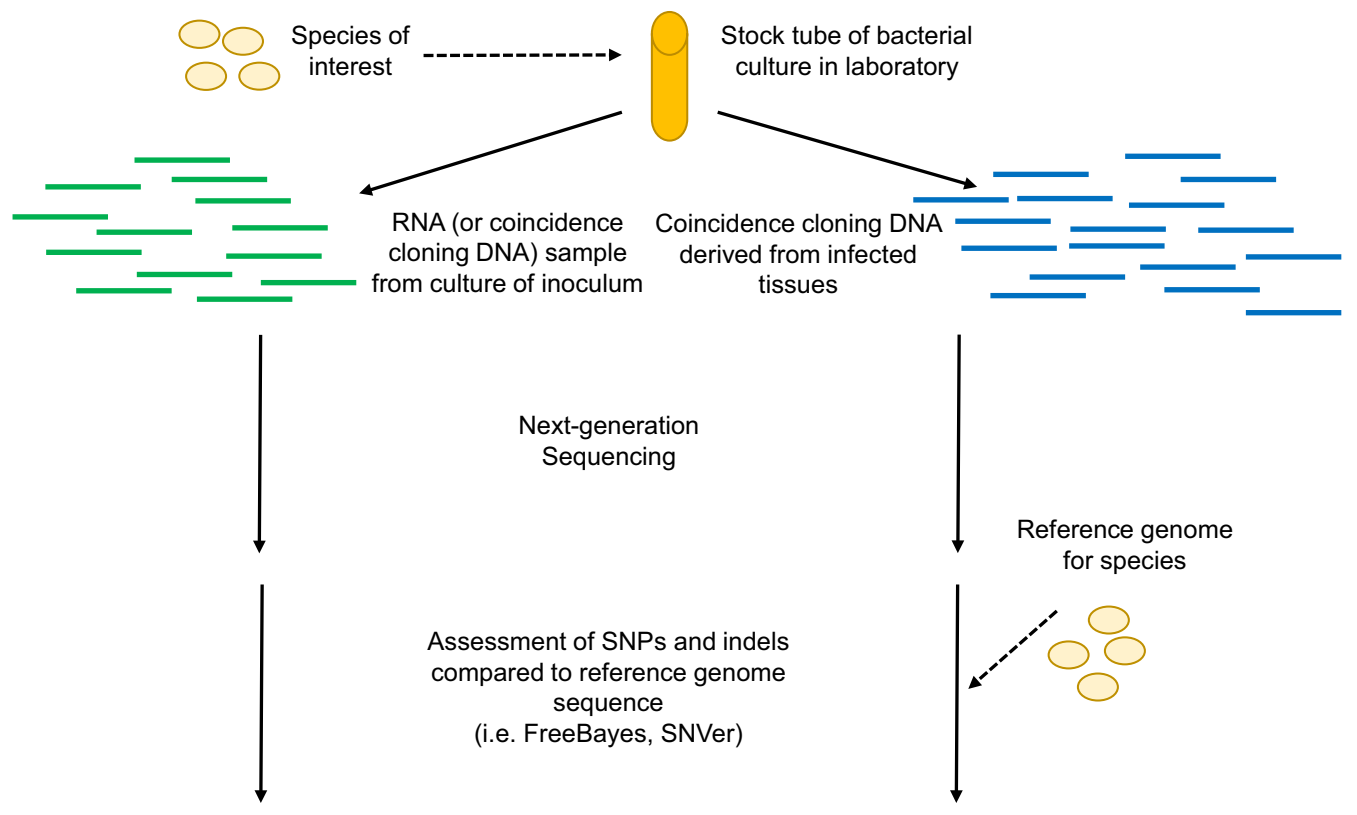

Assess SNP and/or indel tables:

--Does each sample carry most of the identified polymorphisms? (will not be $100 \%$, due to differences in read depth).

--For identified locations, are changes present in $\approx 100 \%$ of reads?

Fig. 5 Schematic of work flow for indel assessment. Diagram depicts steps conducted in the paper to compare the recovered coincidence cloning reads to the original bacterial culture used for goat inoculation in this experiment. In this case, the species of interest was $B$. melitensis, with a culture of strain $16 \mathrm{M}$ from the National Animal Disease Center collection used for goat inoculation. The methodology exploits natural SNP variation between the stock tube culture and the published NCBI reference sequence for B. melitensis strain 16M for SNP (single nucleotide polymorphism) assessment. The procedure is presented as a suggested workflow for application of this methodology to future coincidence cloning experiments assessing samples with low pathogen abundance and, therefore, potential for environmental contamination

exclusively in all of the short-term or all of the long-term samples. Additional file 7 provides the annotation for multiple selected indel loci, presenting the percent of mapped reads carrying the sequence variation in representative samples. Importantly, the presence of gDNA in the heteroduplexes means that at least $50 \%$ of the reads should carry the sequence of the starting inoculum, so indel abundance of $\approx 100 \%$ at individual locations, paired with correspondence with the indels present in the culture data, is indicative of cDNA derived from the inoculated strain. These results indicate that the recovered RNA from the tissue-derived samples is consistent with the $B$. melitensis $16 \mathrm{M}$ cultures that were used to infect the animals. We suggest that the same methodology can alternatively be applied for future analysis using a simple RNA-sequencing run of RNA from the starting bacterial inoculum, as opposed to parallel coincidence cloning. This analysis is of particular value for laboratories processing numerous Brucella isolates.

Second, we completed a clustering analysis to examine how the gene expression profiles for the short-term and long-term samples relate to each other, using the same set of culture-derived samples as a reference group for comparison. Via two means of clustering based on overall gene expression profiles, both the culture and the longterm infection samples each group together, whereas the short-term infection samples exhibit significant scatter (Fig. 6a, b). Despite the dispersion in the case of shortterm samples, DESeq2 analysis of the short-term and long-term samples identifies a subset of differentially expressed genes (Additional file 8). The results suggest both that there are distinct profiles for culture and long-term infection samples, and that this methodology has the capacity to distinguish differential expression between groups.

\section{Validating gene expression patterns from coincidence cloning data}

Next, we wanted to examine the feasibility of using qPCR to validate the profiles of relative gene expression levels generated from coincidence cloning. Therefore, we selected a series of 5 genes, with different levels of 

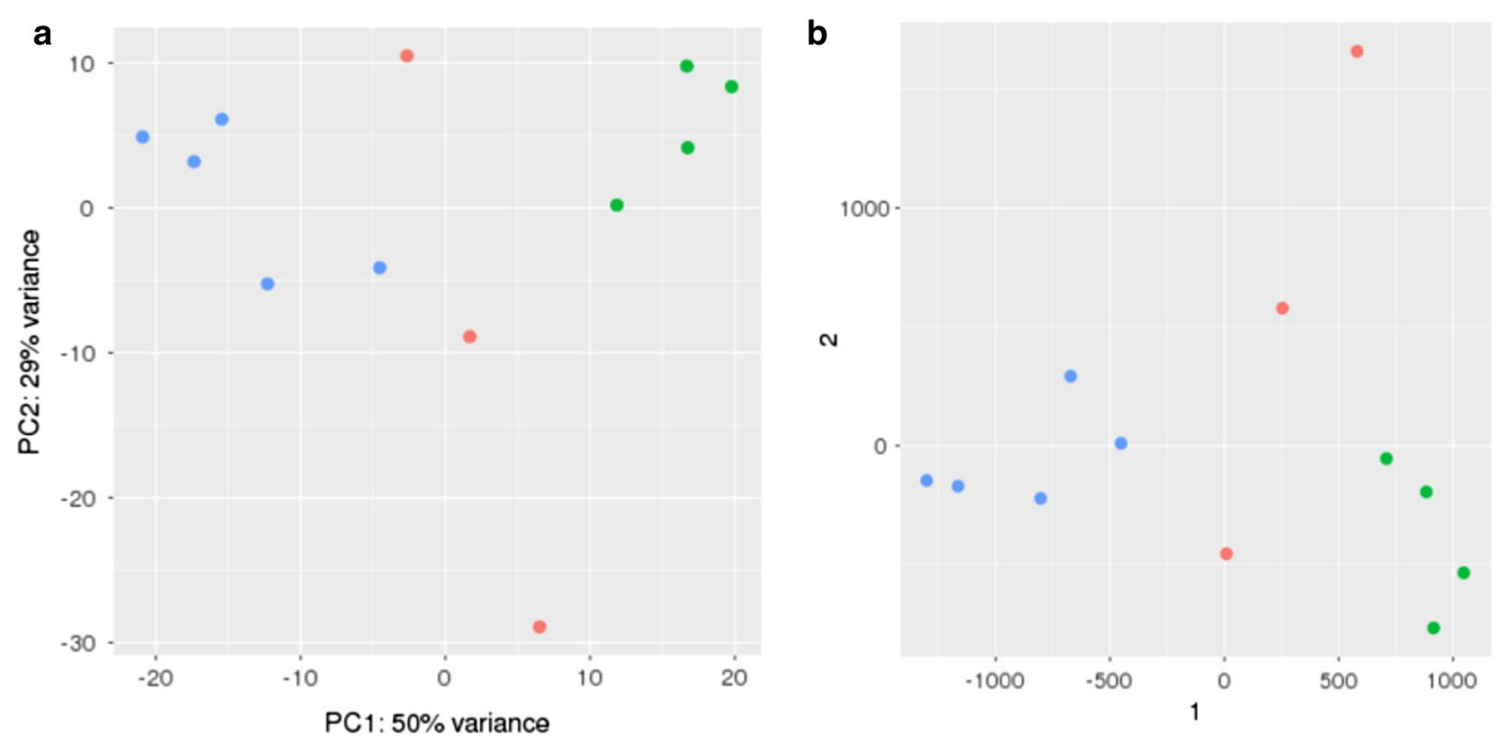

Fig. 6 Clustering analysis of coincidence cloning samples. a Principal component analysis (PCA) plot and $\mathbf{b}$ multidimensional scaling (MDS) plot. The PCA plot used the overall sample distances generated from regularized log-transformation of the gene-wise count data (DESeq2). The MDS plots used the Poisson sample distances generated from the gene-wise count data (DESeq2). Green dots indicate long-term infection samples, red dots indicate short-term infection samples, and blue dots indicate culture samples for comparison

expression predicted from the analysis of the coincidence cloning data, and characterized their relative expression using PCR1 products from each of the long-term infected goat samples. The expression level of each gene was compared to the level of one of the other genes in the set $(e n t A)$, and these results were compared with the relative levels of expression predicted from the (gene sizenormalized) RNA-sequencing data set. The qPCR tests on the PCR1 products indicate good correspondence with the final sequencing results (Fig. 7A). This result suggests that the RNA-seq-characterized gene expression patterns are reflective of at least the PCR1 product.

Generation of the PCR1 product requires two sets of amplification, both in the cDNA preparation step and in the PCR1 amplification itself, which could lead to gene expression determinations that are not representative of the levels of each RNA in the original tissue. Additionally, the PCR1 product is generated after the addition of capture genomic DNA, which is a source of potential contamination. Therefore, we also attempted qRT-PCR reactions using RNA template from short-term infection samples with the entA, ribE, and $d k s A$ primer sets, but did not observe evidence of amplification beyond that in no template control samples (data not shown). Similarly, we did not observe amplification beyond that in no template control reactions for the primers with cDNA template from short-term infection samples. We also wondered whether the same level of "selective suppression of PCR" as observed previously for mycobacterium samples in the PCR1 reaction (repression of amplification of homoduplexes) was present for our Brucella samples. To test this, similar to the validation performed by Azhikina et al. [28], we completed a PCR2 amplification using single, internal primers (Not1Srf or Not1Rsa) on three PCR1 samples from infected goats. Notably, significant amplification was observed in the presence of only a single primer (Fig. 7B). This suggests that the PCR1 reaction did not suppress amplification of all of the genomic DNA that was mixed with the lymph node-derived sample. The larger size of the amplified products also suggests that we could be amplifying some larger genomic DNA or cDNA fragments that have not been digested completely with RsaI. We conclude that there is at least some genomic DNA contamination in the PCR1 product, which would impact the assessment of relative gene expression levels via qPCR.

As a result, validation of gene expression patterns appears to be a challenge for the very low pathogen abundance samples in the Brucella coincidence cloning procedure. However, the appearance of the PCR2 reactions when both primers are used in the reaction (Fig. 7B, lanes $3,6,9$ ) reaffirms that it is a separate set of products, presumably the desired cDNA-genomic DNA heteroduplexes, which are being amplified and highly enriched in the presence of both internal primers. Since RsaI cuts at a 4 base pair sequence (GTAC), recognition sites are expected in the genome every 256 base pairs, consistent with the size of the PCR2 reactions with both primers. 

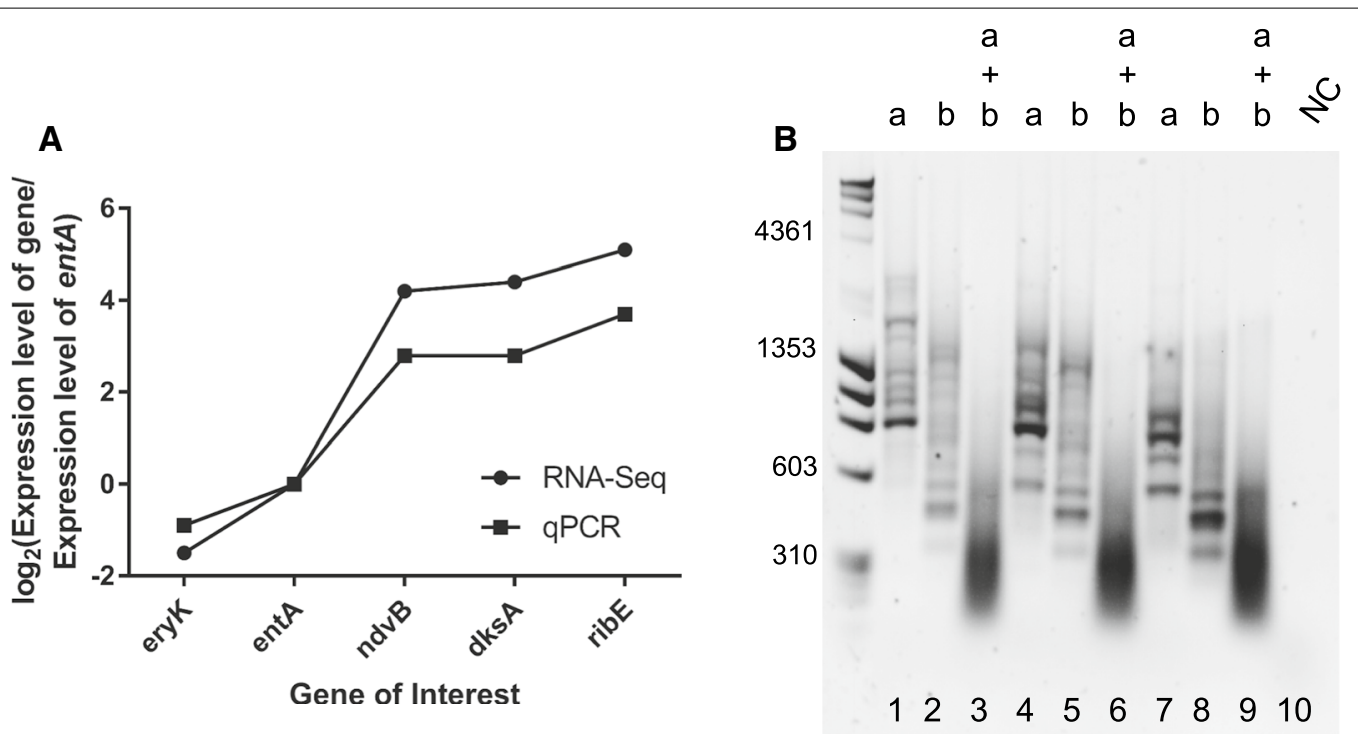

Fig. 7 Assessment of the PCR1 products. A Assessment of gene expression levels in the PCR1 product. Actual vs. predicted gene expression levels of a set of five genes were assessed in the long-term infection samples via qPCR. PCR1 products from each long-term goat sample were amplified with five primer sets for the $n d v B$, ribE, $d k s A$, ent $A$, and eryK genes, as described in "Methods". $\Delta C_{t}$ values were calculated for the expression of each gene relative to the expression level of the ent $A$ gene. The relative gene expression is expressed here as the $\log _{2}$ (expression level of gene of interest/expression level of entA), with closed squares for the qPCR-derived differences in expression and closed circles for the RNA-Seq-derived differences in expression (genes with higher expression than entA are depicted as positive values in this figure). Values were averaged across all four long-term goat samples (four biological replicates) to obtain the data points. B Assessment of suppression in the PCR1 reaction. PCR1 templates from three different tissue-derived samples (lanes 1-3, lanes 4-6, and lanes 7-9) were amplified under the PCR2 reaction parameters (described in "Methods") with either Not1Srf primer (marked as "a"), Not1Rsa primer (marked as "b"), or both primers (marked as "a + b"). NC= negative control reaction, with no template but both primers. Numbers indicated on the left side of the gel indicate the molecular weight of ladder bands in base pairs

Therefore, the majority of the PCR2 products that are used for RNA-sequencing library preparation should reflect the transcripts that are present in the lymph node samples, and this is confirmed by the enrichment of reads mapping to bacterial genes in the RNA-sequencing samples. Additionally, $>99 \%$ of the reads aligned to the $B$. melitensis 16M genome (Table 2), so bacterial transcripts (vs. the eukaryotic host transcripts) have been exponentially enriched in the procedure. In contrast, only about $75 \%$ of the reads generated by pyrosequencing were bacterial in the original application of the procedure to mycobacterial infection by Azhikina et al. [28]; this result suggests that the PCR-based homoduplex suppression was not complete in this previous study as well.

\section{Identification of gene candidates of interest in long-term infection}

Characterization of shifts in pathogen gene expression over time in the host provides the opportunity to identify genes and pathways important in pathogen persistence. First, we examined information provided by this dataset about the relative transcriptional profiles of $B$. melitensis bacteria under culture vs. long-term infection conditions. Our application of the coincidence cloning technique provided a profile of gene expression for $B$. melitensis in long-term culture (Additional files 4,5) that was generated under conditions in which Brucella gDNA was present in vast excess to cDNA, as desired for effective and unbiased hybridization. However, in culturederived samples such as the ones depicted in Fig. 6, the same excess of gDNA is not present. Therefore, to avoid impacts of hybridization bias, we compared the gene expression profile from Brucella recovered after 38 weeks of infection (Additional file 4) to a previously published dataset of gene RPKM values for $B$. melitensis $16 \mathrm{M}$ grown at $37^{\circ} \mathrm{C}$ in acidified culture [52], as an in vitro mimic of macrophage conditions in the absence of other adaptations to the host environment.

We identified a subset of genes that were among the top in expression (normalized to gene length) in our dataset, and simultaneously near the bottom of the list of expression for the acidified in vitro dataset from Liu et al. [52]. Next, we further narrowed genes within that subset to those that were also upregulated $>4$-fold in our long-term lymph node vs. in vitro (nonacidified) culture coincidence cloning dataset. Resulting candidate genes of interest are presented in Table 3 . The majority of the selected genes were not significantly influenced 
Table 3 Candidate genes of interest based on abundance in long-term Brucella samples

\begin{tabular}{|c|c|c|c|c|c|c|c|}
\hline Locus tag & Product name/description & $\begin{array}{l}\text { Rank } \\
\text { in acidified } \\
\text { culture [52] }\end{array}$ & $\begin{array}{l}\text { Rank } \\
\text { in long- } \\
\text { term }\end{array}$ & $\begin{array}{l}\log _{2} \operatorname{Expn} \\
\text { in LT vs. } \\
\text { culture }\end{array}$ & $\begin{array}{l}\text { Growth } \\
\text { phase reg. } \\
\text { [53] }\end{array}$ & Reg. in cattle (4 h) [27] & Reg. in $M \Phi(24 h)$ [54] \\
\hline BMEI0050 & $\begin{array}{l}\text { CobT (Cobalamin biosyn- } \\
\text { thesis) }\end{array}$ & 2043 & 41 & 2.7 & $\mathrm{~N}$ & Mixed effects & No change \\
\hline BMEI0460 & MoxR family protein & 1892 & 42 & 3.1 & $\mathrm{~N}$ & Repressed & Slight repress \\
\hline BMEI0461 & Hypothetical protein & 1971 & 31 & 3.1 & $\mathrm{~N}$ & No change & Slight repress \\
\hline BMEI0828 & $\begin{array}{l}\text { Phosphatidate cytidyltrans- } \\
\text { ferase }\end{array}$ & 2101 & 95 & 5.9 & N & Activated & Slight repress \\
\hline BMEl1817 & $\begin{array}{l}\text { ATP-dependent helicase } \\
\text { HrpB }\end{array}$ & 3100 & 1291 & 6.6 & $\mathrm{~N}$ & Repressed & No change \\
\hline BMEI1896 & Hypothetical protein & 2953 & 17 & 2.8 & $\mathrm{~N}$ & Repressed & No change \\
\hline BMEII0111 & ICC protein family & 2227 & 136 & 3.2 & $\mathrm{~N}$ & Activated & No change \\
\hline BMEII0113 & $\begin{array}{l}\text { sn-Glycerol-3-phosphate } \\
\text { transport system UgpA }\end{array}$ & 3026 & 94 & 3.2 & N & Repressed & No change \\
\hline BMEII0114 & $\begin{array}{l}\text { sn-Glycerol-3-phosphate } \\
\text { transport system UgpE }\end{array}$ & 2611 & 254 & 2.9 & Y & Repressed & No change \\
\hline BMEII0167 & $\begin{array}{l}\text { FlhA2 flagellar biosynthesis } \\
\text { protein }\end{array}$ & 2902 & 71 & 2.9 & $\mathrm{~N}$ & Repressed & No change \\
\hline BMEII0831 & Hypothetical protein & 1937 & 253 & 7.7 & $\mathrm{~N}$ & Activated & No change \\
\hline BMEII0832 & UDP-glucose-4-epimerase & 3128 & 239 & 7.5 & N & Repressed & No change \\
\hline
\end{tabular}

Relevant expression information for each gene candidate is compiled from external data sources as described, plus the coincidence cloning data set presented in this paper. Rank in acidified culture: Rank of gene in Liu et al. [52] expression set, sorted from high (1) to low (3152) by RPKM. Rank in long-term: Rank of gene in averaged long-term expression set from coincidence cloning (CC), sorted from high (1) to low (3264) by gene expression normalized to gene and library size in SeqMonk (FPKM). Log $_{2}$ Expn: $\log _{2}$ (expression in long-term samples/expression in culture-derived samples) for CC dataset, generated as log 2 (FPM for long-term/FPM for culture) in SeqMonk. Growth phase reg: Expresses whether (yes/no) the gene locus was identified as exhibiting a significant and $>2$-fold change in gene expression between log and stationary phase in culture by Rossetti et al. [53]. Reg. in cattle: describes pattern of gene expression observed over the first $4 \mathrm{~h}$. of introduction of cultured $B$. melitensis to cattle intestinal sections [27]. Reg. in macrophages: Describes pattern of gene expression observed $24 \mathrm{~h}$ post-murine macrophage infection, as compared to expression pre-infection in broth culture [54]. Data from Liu et al. [52] reflect actively growing cultures in vitro in Tryptic Soy Broth (fresh media added after subculture from stationary phase), exposed to acid stress like that expected in a macrophage ( $\mathrm{pH}$ 3.4). Data from the culture-derived coincidence cloning (CC) samples was obtained from parallel CC of RNA derived from overnight cultures of the B. melitensis $16 \mathrm{M}$ challenge strain grown in Brucella broth

by growth phase in culture, based on data from Rossetti et al. [53], suggesting that the observed differences are not simply a function of the growth phase of the culture sample selected for comparison. These genes serve as candidates for future study of their roles in the persistence of Brucella in the host. Of particular interest is the phosphatidate cytidylyltransferase gene $(c d s A)$, which is involved in synthesis of phospholipid precursors from sn-glycerol-3-phosphate (the transporters of which are also candidates of interest; Table 3). Indeed, the longterm samples exhibit high levels of expression of genes involved in lipid metabolism (Fig. 4b).

Additionally, we examined the differential gene expression profiles of the short-term and long-term Brucella samples, as outlined in Additional file 8, for genes of interest for B. melitensis persistence in vivo. Specifically, we selected genes from Additional file 8 with (a) a $\mathrm{p}$-value of $<0.01$ for significance (in difference in expression between the short-term and long-term groups) and (b) an increase in expression of $>8$-fold from the shortterm to the long-term condition. In other words, these are genes that exhibit significant upregulation between 4 and 38 weeks post-challenge in the goat (Table 4).
We then compared this list of genes to a list of Brucella virulence factors, based on their mutants' attenuation in mice, macrophages, or HeLa cells, as compiled from the literature by He [55] and Brambila-Tapia et al. [56] (basis for far right column, Table 4). Notably, three of the highly upregulated genes are known virulence genes: BMEI1766 (cysI), BMEII0527 (xseA), and BMEII0089 $(r b s K)$. Other genes in Table 4 may be (a) upregulated in persistent infection but not essential for virulence, or (b) essential for persistence in the long-term goat model, but not essential for virulence in shorter-term models of infection in mice or cells. Indeed, significant disparity is expected between lists of genes required for virulence in short-term infection, and genes that are distinctly upregulated during long-term infection.

Other genes of note in Table 4 include BMEII1029, BMEII0564, and BMEI1816. BMEII1029 encodes 3-deoxy-D-manno-octulosonic-acid transferase; this gene has been demonstrated to contribute to synthesis of lipooligosaccharide for the outer membrane of Moraxella catarrhalis, and was important in virulence in a mouse model [57]. A recent paper on B. abortus demonstrated that the homolog of PutA (BMEII0564 in B. melitensis), 
Table 4 Candidate genes of interest in persistence based on upregulation in long-term (vs. short-term) samples

\begin{tabular}{|c|c|c|c|}
\hline Locus tag & Product name/description & $\log _{2}$ (fold change) & $\begin{array}{l}\text { Listed } \\
\text { as virulence } \\
\text { gene? }\end{array}$ \\
\hline BMEII1062 & (S)-2-hydroxy-acid oxidase subunit GlcE & 4.8 & No \\
\hline BMEII1029 & 3-Deoxy-D-manno-octulosonic-acid transferase & 4.3 & No \\
\hline BMEl1927 & Enoyl-CoA hydratase & 4.1 & No \\
\hline BMEII0089 & Ribokinase (rbsK) & 4.1 & Yes \\
\hline BMEII0086 & Galactoside transport system permease MgIC & 4.0 & No \\
\hline BMEl1816 & Sensory transduction protein kinase & 4.0 & No \\
\hline BMEII0524 & Hypothetical protein & 3.7 & No \\
\hline BMEII0860 & Oligopeptide transport system permease protein AppB & 3.7 & No \\
\hline BMEII0862 & Dihydrodipicolinate synthase & 3.6 & No \\
\hline BMEI0234 & Hypothetical cytosolic protein & 3.5 & No \\
\hline BMEl1766 & Sulfite reductase (ferredoxin; cysl) & 3.4 & Yes \\
\hline BMEII0527 & Exodeoxyribonuclease VII large subunit (xseA) & 3.4 & Yes \\
\hline BMEII0526 & Transcriptional regulatory protein, LysR family & 3.4 & No \\
\hline BMEI0171 & Ribosomal protein L11 methyltransferase & 3.4 & No \\
\hline BMEl1926 & Hydroxymethylglutaryl-CoA lyase & 3.4 & No \\
\hline BMEl1817 & ATP_dependent helicase HrpB & 3.3 & No \\
\hline BMEI0173 & Ycil-like protein & 3.3 & No \\
\hline BMEl1925 & $\begin{array}{l}\text { Acetyl-CoA carboxylase alpha chain/propionyl-CoA carboxylase alpha } \\
\text { chain }\end{array}$ & 3.3 & No \\
\hline BMEII0564 & $\begin{array}{l}\text { Bifunctional proline dehydrogenase/pyrroline-5-carboxylate dehydroge- } \\
\text { nase (putA) }\end{array}$ & 3.2 & No \\
\hline BMEII0079 & Isochorismatase & 3.2 & No \\
\hline BMEI0248 & FOF1 ATP synthase subunit delta & 3.1 & No \\
\hline BMEII0864 & Oligopeptide transport ATP-binding protein AppF & 3.1 & No \\
\hline BMEII1030 & Putative lipoprotein & 3.0 & No \\
\hline BMEII0084 & Basic membrane protein A precursor & 3.0 & No \\
\hline BMEII0083 & Basic membrane protein A precursor & 3.0 & No \\
\hline
\end{tabular}

Genes are listed in the order of fold-effect, with the fold change reflecting an increase in expression in the long-term samples in each case (see Additional file 8 for details on differential gene expression analysis; $\log _{2}$ (fold effect) values are displayed based on the analysis in Additional file 8). Gene descriptions are compiled from the Brucella Bioinformatics Portal (www.phidias.us)

an L-proline dehydrogenase, was important in the replication and survival of the bacterium in the murine host [58]. Finally, the protein product encoded by BMEI1816 is a homolog to the $\operatorname{RegB}$ sensor histidine kinase in $B$. suis; the RegA/RegB system in B. suis is involved in adaptation to oxygen depletion, and is required for murine chronic infection [59]. Recent work suggests that the $\mathrm{RegB} / \mathrm{A}$ system is critical for adaptation to the conditions of chronic infection in the host, in response to detection of low oxygen levels [60].

\section{Discussion}

In this paper, we provide the first application of the coincidence cloning technique to the analysis of $B$. melitensis strain 16M from an infected animal host. This is also the first characterization of Brucella RNA from bacterial cells that have disseminated in infection to lymph nodes. We demonstrate the ability to recover sufficient Brucella
RNA from infected host lymph nodes for the coincidence cloning technique. Coincidence cloning enabled us to obtain sequencing reads sufficient to characterize in vivo Brucella gene expression across the genome, despite the extremely low levels of starting material. Additionally, we developed a rapid workflow, using the analysis of indels, to assess the identity of the reads recovered by coincidence cloning as the input strain.

The work presented here utilized two groups of $B$. melitensis 16M-infected goats: a short-term group (4 weeks post-challenge) and a long-term group (38 weeks post-challenge). In the short-term group, bacterial colonization of infected tissues ranged from $10^{3}$ to $10^{8} \mathrm{CFU} / \mathrm{g}$, consistent with our previous findings $[61,62]$. Interestingly, none of the tissues analyzed in the long-term group yielded culturable bacteria, using the homogenization methods described here. However, these tissues tested positive for $B$. melitensis $16 \mathrm{M}$ via the 
coincidence cloning technique. This raises two possible scenarios: either the culture techniques utilized in this paper are not sensitive enough at this stage of infection, or the recovered nucleic acid reflects low levels of background contamination. To determine bacterial load in this study, $1 \mathrm{~g}$ of whole tissue was homogenized in $2 \mathrm{ml}$ of PBS, and serial dilutions of this homogenate were plated. The use of glass (Dounce) homogenizers to grind tissue typically preserves organelle structure, so the inability to recover Brucella from the long-term tissue could indicate difficulties in recovering bacteria from their location in vesicles inside of macrophages. In contrast, the TRIzol lysis buffer combined with mechanical homogenization in our RNA extraction protocol would be able to recover nucleic acid from the intracellular (and intravesicular) environment. In future work, we would consider performing enrichment steps, such as selective lysing of host cells or preincubation in enrichment media prior to plating, to increase bacterial yield.

While background contamination is a reasonable concern, multiple lines of evidence indicate that the isolated nucleic acids did not originate from environmental contaminants. First, potential contaminating nucleic acids would more likely be stable genomic DNA, which would be removed or at least highly reduced during the DNase treatment step. The PCR amplification steps (PCR1 and 2) in the coincidence cloning procedure also limit amplification to linker-attached cDNAs; therefore, any potential contaminants introduced during later stages of the procedure would not be amplified. In addition, the RNA-Seq reads correspond with the sequence of the B. melitensis $16 \mathrm{M}$ isolate that was used to challenge the animals, as determined by indel analysis of the transcriptome (Additional file 6). Finally, we observe a distinct profile for the long-term infection samples when gene expression profiles are analyzed by principal component and multidimensional scaling analyses (Fig. 6). While we cannot completely exclude the possibility that the profiles result from contaminating RNA in the samples, the evidence presented above supports the conclusion that we are observing nucleic acid isolated and amplified from the tissue samples, despite the lack of culturable bacteria.

Recently, the use of dual RNA-seq methods, in which combined samples can be analyzed by deep sequencing to assess both host and pathogen gene expression profiles, has expanded to assess multiple types of pathogens [63]. In some of these cases, selective depletion of host transcripts was utilized. While the majority of this work has focused on in vitro infection of cells, in the past few years, analysis has expanded to include in vivo infections in the case of certain pathogens (for example, Toxoplasma gondii [64], Yersinia pseudotuberculosis [65] and Pseudomonas aeruginosa [66]). In the case of
Brucella infection, Rossetti et al. characterized changes in bacterial and pathogen transcriptomes, but this was performed over the course of a $4 \mathrm{~h}$ time period subsequent to introduction of $3 \times 10^{9} \mathrm{CFU}$ of bacteria [27]. The very low levels of Brucella present during longterm infection present additional challenges for sample analysis. With the use of coincidence cloning, we were able to obtain over 1 million Brucella-specific read pairs from very low abundance samples, and were also able to select for Brucella transcripts as opposed to transcripts from other potentially contaminating bacteria. Thus, the coincidence cloning procedure may have a niche in terms of usage for very low abundance mixed samples. Future work comparing sensitivity and gene expression patterns between the coincidence cloning method and the selective amplification method described by Rossetti et al. [29] would also be useful in advancing Brucella transcriptome profiling.

However, the inability to validate gene expression patterns directly from RNA or cDNA samples in cases with extremely low ratios of bacterial:host RNA makes it difficult to assess the impact of potential biases introduced during the annealing and amplification steps of the coincidence cloning procedure. Therefore, we propose that the best option for future studies with Brucella is to collect a series of samples across the time course of infection, as opposed to comparisons to the gene expression in bacterial pure cultures. Then, impacts of gene recovery bias will be less critical, since relative changes in expression across the infection time course will be the basis for identification of genes of interest in bacterial virulence. In the comparison of short-term and long-term gene expression profiles conducted here, as a first look at potential genes of interest for persistence, genes that are upregulated in long-term vs. short-term infection are potential candidates for deletion in brucellosis vaccine development, as their deletion has the potential to disrupt establishment of persistent infection without compromising early development of a protective response against the vaccine strain.

\section{Conclusions}

The majority of transcriptomic experiments in $B$. melitensis have examined changes in gene expression in the initial stages of infection. However, Brucella sets up a persistent infection in many cases, with host immune responses occurring over time frames of weeks as opposed to days. Therefore, an understanding of pathogen gene expression changes over the long term is important in our understanding of persistent infections.

Here, we demonstrate the application of the coincidence cloning technique to long-term Brucella infections, describe transcriptional profiles of bacteria in 
lymph nodes from both long-term and shorter-term infections, and discuss challenges and potential solutions related to the analysis of samples with very low pathogen nucleic acid abundance. We also identify gene candidates of interest exhibiting unexpectedly high transcriptional abundance in long-term samples, including genes involved in lipid metabolism, or exhibiting significant upregulation of expression in long-term infection as compared to short-term infection, such as proline utilization and cellular signaling (bacterial two-component systems) genes that have been recently implicated in other model systems for Brucella infection. These gene candidates will serve as starting points for characterization of changing RNA profiles over time in different Brucella species. Future extension of this study to capture a time course of samples from Brucella-infected animals may allow for identification of distinct stages of infection via transcriptional profiling. This type of information would be highly informative in understanding how Brucella spp. adapt to their intracellular environment in the mammalian host, and in identifying which genes are critical for their maintenance and survival. Characterization of such genes could identify important targets for therapeutic intervention, as well as for modification in vaccine development to reduce host persistence of attenuated strains.

\section{Additional files}

\begin{abstract}
Additional file 1: Table S1. RIN scores for extracted supramammary lymph node (SMLN) samples: table includes information regarding goat number, experimental group and the RIN score for each SMLN extracted and used in the study.
\end{abstract}

Additional file 2: Table S2. List of primers used in all experiments: table includes a full list of all primers, and their respective sequences, utilized in the study.

Additional file 3: Table S3. RNA quality and yields from B. melitensisinfected goat samples.

Additional file 4. Gene expression values for short- and long-term goat samples. Annotated probe table prepared for coincidence cloning samples for goats 1-3 (short-term) and goats 4-7 (long-term) using SegMonk. Libraries were treated as paired-end upon loading into SegMonk. Quantitation was performed using the RNA-Sequencing pipeline in SegMonk, using the option for normalization of values to gene size (per kilobase of transcript per million mapped reads, or FPKM, based on SeqMonk documentation), and expression values are expressed as $\log _{2}$ transformations of FPKM values. Start and end columns indicate locations of each quantitated feature in the B. melitensis $16 \mathrm{M}$ reference genome.

Additional file 5. Sorted gene expression tables of top 100 genes by relative expression. Average gene length-normalized expression values (FPKM, calculated by SegMonk) for the short-term and long-term coincidence cloning samples, generated as described in Additional file 4, were sorted by expression level for the short-term (left-hand columns) or the long-term (right-hand columns) samples. COG (Cluster of Orthologous Group) designations, as determined via the PHIDIAS Brucella Bioinformatics Portal (www.phidias.us/bbp/), are annotated. The top 100 genes from each group in expression levels are provided. We note that there are challenges with the use of read data in FPKM/RPKM averaged across multiple samples, as discussed by Wagner et al. [67]. However, as depicted in Additional file 4, average FPKM values for each sample were very similar between biological replicates. We also completed an analysis in which the rank orders of gene expression were determined for each individual sample, and then genes were sorted by the lowest average rank order of expression. 96\% of the long-term top 100 genes and $90 \%$ of the short-term top 100 genes were identical between the two methods. COG category single letter associations: amino acid transport and metabolism (E), carbohydrate transport and metabolism $(G)$, cell cycle control and cell division, chromosome partitioning (D), cell motility (N), cell wall/membrane/envelope biogenesis (M), chromatin structure and dynamics (B), coenzyme transport and metabolism $(H)$, cytoskeleton (Z), defense mechanisms ( $\mathrm{V}$ ), energy production and conversion (C), extracellular structures (W), function unknown (S), general function and prediction only (R), inorganic ion transport and metabolism (P), intracellular trafficking, secretion and vesicular transport (U), lipid transport and metabolism (I), nucleotide transport and metabolism (F), post-translational modification, protein turnover, chaperones $(\mathrm{O})$, RNA processing and modification (A), replication, recombination and repair (L), secondary metabolites biosynthesis, transport and catabolism $(\mathrm{Q})$, signal transduction mechanisms $(\mathrm{T})$, transcription $(\mathrm{K})$, translation, ribosomal structure and biogenesis $(\mathrm{J})$.

Additional file 6. Indel analysis table across coincidence cloning samples. This table of indels present in the coincidence cloning reads was generated by SNVer analysis, as described in Methods, with only indels passing the read depth and significance filters displayed here. Columns A and B indicate the reference location of each indel on the chromosome (either l, indicated by NC_003317.1, or II, indicated by NC_003318.1). A "0" indicates the absence of the indel as compared to the B. melitensis $16 \mathrm{M}$ reference genome (matching the reference sequence) and $a^{\prime \prime} 1$ "indicates the presence of the indel. "Cultures 1-5" are B. melitensis broth culture-derived coincidence cloning samples, and the remaining samples are listed by their goat number. Rows in which all samples carried the designated indel are colored in green, and rows in which all but one of the samples carried the designated indel are colored in yellow. Please note that in cases where some samples did not exhibit the indel, this can be due to a read depth below the cutoff of $>50$ at the indel location for that sample, as used for the SNVer filter.

Additional file 7. Additional indel analysis. Data is presented from FreeBayes for a set of 5 selected indels identified by both FreeBayes and SNVer for coincidence cloning reads as compared to the B. melitensis $16 \mathrm{M}$ reference genome. For each of the samples indicated (provided as examples), the following are displayed: the total reads at the indel location from the RNA-sequencing sample, as mapped to the B. melitensis genome; the number of reads carrying the alternative (indel) allele; and the percent of mapped reads exhibiting the indel. $>92 \%$ of reads in each displayed location carried the indel of interest.

Additional file 8. Analysis of differential gene expression comparison between short-term and long-term samples. Table presents the results of DESeq2 differential expression analysis comparing the group of shortterm samples (goats 1-3) and long-term samples (goats 4-7). Data are sorted by the adjusted $p$-value for each comparison (Column G), from smallest to largest. Genes are identified by the locus tag in Column A. The $\log _{2}$ FoldChange (Column C) indicates the $\log _{2}$ of the differential gene expression of (Long-term/Short-term) samples.

\section{Abbreviations}

CC: coincidence cloning; SMLN: supramammary lymph node.

\section{Authors' contributions}

PB performed data analysis and manuscript preparation; CV performed PCR experiments, data analysis and manuscript preparation; DF collected samples and performed the coincidence cloning procedure; DB and DA coordinated RNA-sequencing sample submission and completed bioinformatics analysis; and SO performed animal experiments and collected samples. All authors read and approved the final manuscript. 


\author{
Acknowledgements \\ The authors would like to thank Darl Pringle, Lilia Walther, and the Animal \\ Resource Unit (ARU) at the National Animal Disease Center for their technical \\ support, as well as the staff of the lowa State sequencing facility for next- \\ generation sequencing.
}

\section{Competing interests}

The authors declare that they have no competing interests. All brand names provided in the manuscript are included for purposes of experimental reproducibility and transparency, and do not indicate official endorsement by the USDA.

\section{Availability of data and materials}

The Additional files included with this manuscript (Additional file 4 in particular) present full expression profiles for the lymph node coincidence cloning sets for the samples. The coincidence cloning data is not a standard gene expression set in terms of upload to public databases (i.e., not a direct RNA-sequencing data set); however, we will provide raw FASTQ and/or BAM alignment files for samples upon request to the corresponding author.

\section{Consent for publication}

Not applicable.

\section{Ethics approval and consent to participate}

The study did not include use of human subjects or associated consent issues. As noted in "Methods", work on animals (goat infection study) was reviewed and approved by the Institutional Animal Care and Use Committee (IACUC) of the National Animal Disease Center, US Department of Agriculture, in Ames, IA. The relevant associated protocol number is ARS-2719.

\section{Funding}

The work presented here was funded by intramural funds of the United States Department of Agriculture (USDA).

\section{Publisher's Note}

Springer Nature remains neutral with regard to jurisdictional claims in published maps and institutional affiliations.

Received: 5 October 2017 Accepted: 24 July 2018

Published online: 01 August 2018

\section{References}

1. Pappas $G$. The changing Brucella ecology: novel reservoirs, new threats. Int J Antimicrob Agents. 2010;36(Suppl 1):S8-11.

2. Neglected tropical diseases. http://www.who.int/neglected_diseases/ zoonoses/infections_more/en/. Accessed Apr 2018.

3. von Bargen K, Gorvel JP, Salcedo SP. Internal affairs: investigating the Brucella intracellular lifestyle. FEMS Microbiol Rev. 2012;36(3):533-62.

4. Ahmed W, Zheng K, Liu ZF. Establishment of chronic infection: Brucella's stealth strategy. Front Cell Infect Microbiol. 2016;6:30.

5. Barquero-Calvo E, Chaves-Olarte E, Weiss DS, Guzman-Verri C, ChaconDiaz C, Rucavado A, Moriyon I, Moreno E. Brucella abortus uses a stealthy strategy to avoid activation of the innate immune system during the onset of infection. PLoS ONE. 2007;2(7):e631.

6. Billard E, Dornand J, Gross A. Interaction of Brucella suis and Brucella abortus rough strains with human dendritic cells. Infect Immun. 2007;75(12):5916-23.

7. Carvalho Neta AV, Stynen AP, Paixao TA, Miranda KL, Silva FL, Roux CM, Tsolis RM, Everts RE, Lewin HA, Adams LG, et al. Modulation of the bovine trophoblastic innate immune response by Brucella abortus. Infect Immun. 2008;76(5):1897-907.

8. Chaudhary A, Ganguly K, Cabantous S, Waldo GS, Micheva-Viteva SN, Nag K, Hlavacek WS, Tung CS. The Brucella TIR-like protein TcpB interacts with the death domain of MyD88. Biochem Biophys Res Commun. 2012;417(1):299-304.

9. Kaplan-Turkoz B, Koelblen T, Felix C, Candusso MP, O'Callaghan D, Vergunst AC, Terradot L. Structure of the toll/interleukin 1 receptor (TIR) domain of the immunosuppressive Brucella effector BtpA/Btp1/TcpB. FEBS Lett. 2013;587(21):3412-6.

10. Rossetti CA, Drake KL, Adams LG. Transcriptome analysis of HeLa cells response to Brucella melitensis infection: a molecular approach to understand the role of the mucosal epithelium in the onset of the Brucella pathogenesis. Microbes Infect. 2012;14(9):756-67.

11. Radhakrishnan GK, Yu Q, Harms JS, Splitter GA. Brucella TIR domain-containing protein mimics properties of the toll-like receptor adaptor protein TIRAP. J Biol Chem. 2009;284(15):9892-8.

12. Salcedo SP, Marchesini MI, Lelouard H, Fugier E, Jolly G, Balor S, Muller A, Lapaque N, Demaria O, Alexopoulou L, et al. Brucella control of dendritic cell maturation is dependent on the TIR-containing protein Btp1. PLoS Pathog. 2008;4(2):e21.

13. Sengupta D, Koblansky A, Gaines J, Brown T, West AP, Zhang D, Nishikawa T, Park SG, Roop RM 2nd, Ghosh S. Subversion of innate immune responses by Brucella through the targeted degradation of the TLR signaling adapter, MAL. J Immunol. 2010;184(2):956-64.

14. Barbier T, Nicolas C, Letesson JJ. Brucella adaptation and survival at the crossroad of metabolism and virulence. FEBS Lett. 2011;585(19):2929-34.

15. Hanna N, Ouahrani-Bettache S, Drake KL, Adams LG, Kohler S, Occhialini A. Global Rsh-dependent transcription profile of Brucella suis during stringent response unravels adaptation to nutrient starvation and cross-talk with other stress responses. BMC Genomics. 2013;14:459.

16. Kohler S, Foulongne V, Ouahrani-Bettache S, Bourg G, Teyssier J, Ramuz M, Liautard JP. The analysis of the intramacrophagic virulome of Brucella suis deciphers the environment encountered by the pathogen inside the macrophage host cell. Proc Natl Acad Sci USA. 2002;99(24):15711-6.

17. Lamontagne J, Forest A, Marazzo E, Denis F, Butler H, Michaud JF, Boucher L, Pedro I, Villeneuve A, Sitnikov D, et al. Intracellular adaptation of Brucella abortus. J Proteome Res. 2009;8(3):1594-609.

18. DelVecchio VG, Kapatral V, Redkar RJ, Patra G, Mujer C, Los T, Ivanova N, Anderson I, Bhattacharyya A, Lykidis A, et al. The genome sequence of the facultative intracellular pathogen Brucella melitensis. Proc Natl Acad Sci USA. 2002;99(1):443-8.

19. Paulsen IT, Seshadri R, Nelson KE, Eisen JA, Heidelberg JF, Read TD, Dodson RJ, Umayam L, Brinkac LM, Beanan MJ, et al. The Brucella suis genome reveals fundamental similarities between animal and plant pathogens and symbionts. Proc Natl Acad Sci USA. 2002;99(20):13148-53.

20. Delrue RM, Lestrate P, Tibor A, Letesson JJ, De Bolle X. Brucella pathogenesis, genes identified from random large-scale screens. FEMS Microbiol Lett. 2004;231(1):1-12.

21. Gorvel JP, Moreno E. Brucella intracellular life: from invasion to intracelIular replication. Vet Microbiol. 2002;90(1-4):281-97.

22. Seleem MN, Boyle SM, Sriranganathan N. Brucella: a pathogen without classic virulence genes. Vet Microbiol. 2008;129(1-2):1-14.

23. Foulongne V, Bourg G, Cazevieille C, Michaux-Charachon S, O'Callaghan D. Identification of Brucella suis genes affecting intracellular survival in an in vitro human macrophage infection model by signature-tagged transposon mutagenesis. Infect Immun. 2000;68(3):1297-303.

24. Lestrate P, Dricot A, Delrue RM, Lambert C, Martinelli V, De Bolle X, Letesson JJ, Tibor A. Attenuated signature-tagged mutagenesis mutants of Brucella melitensis identified during the acute phase of infection in mice. Infect Immun. 2003:71(12):7053-60.

25. Zygmunt MS, Hagius SD, Walker JV, Elzer PH. Identification of Brucella melitensis $16 \mathrm{M}$ genes required for bacterial survival in the caprine host. Microbes Infect. 2006;8(14-15):2849-54.

26. Kim S, Watarai M, Kondo Y, Erdenebaatar J, Makino S, Shirahata T. Isolation and characterization of mini-Tn5Km2 insertion mutants of Brucella abortus deficient in internalization and intracellular growth in HeLa cells. Infect Immun. 2003;71(6):3020-7.

27. Rossetti CA, Drake KL, Lawhon SD, Nunes JS, Gull T, Khare S, Adams LG. Systems biology analysis of temporal in vivo Brucella melitensis and bovine transcriptomes predicts host: pathogen protein-protein interactions. Front Microbiol. 2017:8:1275.

28. Azhikina T, Skvortsov T, Radaeva T, Mardanov A, Ravin N, Apt A, Sverdlov E. A new technique for obtaining whole pathogen transcriptomes from infected host tissues. Biotechniques. 2010;48(2):139-44.

29. Rossetti CA, Galindo CL, Garner HR, Adams LG. Selective amplification of Brucella melitensis mRNA from a mixed host-pathogen total RNA. BMC Res Notes. 2010;3:244 
30. Banaiee N, Jacobs WR, Ernst JD. Regulation of Mycobacterium tuberculosis whiB3 in the mouse lung and macrophages. Infect Immun. 2006;74(11):6449-57.

31. Skvortsov TA, Ignatov DV, Majorov KB, Apt AS, Azhikina TL. Mycobacterium tuberculosis transcriptome profiling in mice with genetically different susceptibility to tuberculosis. Acta Naturae. 2013;5(2):62-9.

32. Kuzdas CD, Morse EV. A selective medium for the isolation of brucellae from contaminated materials. J Bacteriol. 1953;66(4):502-4.

33. Alton $\mathrm{GG}$, Jones $\mathrm{LM}$, Angus RD, Verger JM. Techniques for the brucellosis laboratory. Paris: Institut National de la Recherche Agronomique; 1988

34. Lee IK, Olsen SC, Bolin CA. Effects of exogenous recombinant interleukin-12 on immune responses and protection against Brucella abortus in a murine model. Can J Vet Res. 2001;65(4):223-8.

35. Olsen SC, Hennager SG. Immune responses and protection against experimental Brucella suis biovar 1 challenge in nonvaccinated or B. abortus strain RB51-vaccinated cattle. Clin Vaccine Immunol. 2010;17(12):1891-5.

36. Stoffregen WC, Johnson CS, Olsen SC. Immunogenicity and safety of a natural rough mutant of Brucella suis as a vaccine for swine. Res Vet Sci. 2013:95(2):451-8.

37. Bolger AM, Lohse M, Usadel B. Trimmomatic: a flexible trimmer for Illumina sequence data. Bioinformatics. 2014;30(15):2114-20.

38. Langmead B, Salzberg SL. Fast gapped-read alignment with Bowtie 2. Nat Methods. 2012;9(4):357-9.

39. Anders S, Pyl PT, Huber W. HTSeq - a python framework to work with high-throughput sequencing data. Bioinformatics. 2015;31(2):166-9

40. Bioinformatics B: SeqMonk. 1.35 edn. https://www.bioinformatics.babra ham.ac.uk/projects/seqmonk/. Babraham Institute; 2017: a tool to visualize and analyze high throughput mapped sequence data.

41. R: A language and environment for statistical computing. R Foundation for Statistical Computing. https://www.R-project.org/.

42. Love MI, Huber W, Anders S. Moderated estimation of fold change and dispersion for RNA-seq data with DESeq2. Genome Biol. 2014;15(12):550.

43. gplots: Various R programming tools for plotting data. https://CRAN.Rproject.org/package $=$ gplots.

44. Witten D. PoiClaClu: classification and clustering of sequencing data based on a Poisson model. R package version 1.0.2 edn; 2013.

45. Neuwirth E. RColorBrewer: ColorBrewer palettes. R package version 1.1-2 edn; 2014.

46. Bache $\mathrm{SM}$, Wickham H. magrittr: a forward-pipe operator for R. R package version 1.5 edn; 2014

47. Gentleman R, Carey V, Huber W, Hahne F. genefilter: methods for filtering genes from high-throughput experiments. R package version 1.58.1 edn; 2017.

48. Kolde R. pheatmap: pretty heatmaps. R package version 1.0.8 edn; 2015

49. Garrison E, Marth G. Haplotype-based variant detection from short-read sequencing. arXiv:12073907; 2012.

50. Wei Z, Wang W, Hu P, Lyon GJ, Hakonarson H. SNVer: a statistical tool for variant calling in analysis of pooled or individual next-generation sequencing data. Nucleic Acids Res. 2011;39(19):e132.

51. Wang X, Li X, Liu S, Ren H, Yang M, Ke Y, Huang L, Liu C, Liu B, Chen Z. Ultrasensitive detection of bacteria by targeting abundant transcripts. Sci Rep. 2016;6:20393.
52. Liu W, Dong H, Li J, Ou Q, Lv Y, Wang X, Xiang Z, He Y, Wu Q. RNA-seq reveals the critical role of OtpR in regulating Brucella melitensis metabolism and virulence under acidic stress. Sci Rep. 2015:5:10864.

53. Rossetti CA, Galindo CL, Lawhon SD, Garner HR, Adams LG. Brucella melitensis global gene expression study provides novel information on growth phase-specific gene regulation with potential insights for understanding Brucella:host initial interactions. BMC Microbiol. 2009:9:81.

54. Eskra L, Covert J, Glasner J, Splitter G. Differential expression of iron acquisition genes by Brucella melitensis and Brucella canis during macrophage infection. PLOS ONE. 2012;7(3):e31747.

55. He Y. Analyses of Brucella pathogenesis, host immunity, and vaccine targets using systems biology and bioinformatics. Front Cell Infect Microbiol. 2012;2:2

56. Brambila-Tapia AJ, Armenta-Medina D, Rivera-Gomez N, Perez-Rueda E. Main functions and taxonomic distribution of virulence genes in Brucella melitensis 16M. PLoS ONE. 2014;9(6):e100349.

57. Peng D, Choudhury BP, Petralia RS, Carlson RW, Gu XX. Roles of 3-deoxyD-manno-2-octulosonic acid transferase from Moraxella catarrhalis in lipooligosaccharide biosynthesis and virulence. Infect Immun. 2005:73(7):4222-30

58. Caudill MT, Budnick JA, Sheehan LM, Lehman CR, Purwantini E, Mukhopadhyay B, Caswell CC. Proline utilization system is required for infection by the pathogenic alpha-proteobacterium Brucella abortus. Microbiology. 2017;163(7):970-9.

59. Abdou E, Deredjian A, de Bagues MPJ, Kohler S, Jubier-Maurin V. RegA, the regulator of the two-component system RegB/RegA of Brucella suis, is a controller of both oxidative respiration and denitrification required for chronic infection in mice. Infect Immun. 2013;81(6):2053-61.

60. Abdou E, de Bagues MPJ, Martinez-Abadia I, Ouahrani-Bettache S, Pantesco V, Occhialini A, Al Dahouk S, Kohler S, Jubier-Maurin V. RegA plays a key role in oxygen-dependent establishment of persistence and in isocitrate lyase activity, a critical determinant of in vivo Brucella suis pathogenicity. Front Cell Infect Microbiol. 2017;7:186.

61. Olsen SC, Johnson C. Comparison of abortion and infection after experimental challenge of pregnant bison and cattle with Brucella abortus strain 2308. Clin Vaccine Immunol. 2011;18(12):2075-8.

62. Olsen SC, Johnson CS. Efficacy of dart or booster vaccination with strain RB51 in protecting bison against experimental Brucella abortus challenge. Clin Vaccine Immunol. 2012;19(6):886-90.

63. Westermann AJ, Barquist L, Vogel J. Resolving host-pathogen interactions by dual RNA-seq. PLoS Pathog. 2017;13(2):e1006033.

64. Pittman KJ, Aliota MT, Knoll LJ. Dual transcriptional profiling of mice and Toxoplasma gondii during acute and chronic infection. BMC Genomics. 2014;15:806.

65. Nuss AM, Heroven AK, Dersch P. RNA regulators: formidable modulators of yersinia virulence. Trends Microbiol. 2017;25(1):19-34.

66. Damron FH, Oglesby-Sherrouse AG, Wilks A, Barbier M. Dual-seq transcriptomics reveals the battle for iron during Pseudomonas aeruginosa acute murine pneumonia. Sci Rep. 2016:6:39172.

67. Wagner GP, Kin K, Lynch VJ. Measurement of mRNA abundance using RNA-seq data: RPKM measure is inconsistent among samples. Theory Biosci. 2012;131(4):281-5.

Ready to submit your research? Choose BMC and benefit from

- fast, convenient online submission

- thorough peer review by experienced researchers in your field

- rapid publication on acceptance

- support for research data, including large and complex data types

- gold Open Access which fosters wider collaboration and increased citations

- maximum visibility for your research: over 100M website views per year

At BMC, research is always in progress.

Learn more biomedcentral.com/submissions 